Discussion Paper No. 16-063

Cartel Cases and the Cartel Enforcement Process in the European Union 2001 - 2015: A Quantitative Assessment

Michael Hellwig and Kai Hüschelrath

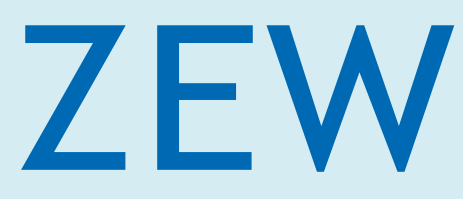

Zentrum für Europäische Wirtschaftsforschung $\mathrm{GmbH}$ Centre for European Economic Research 
Discussion Paper No. 16-063

\section{Cartel Cases and the Cartel Enforcement Process in the European Union 2001 - 2015: A Quantitative Assessment}

Michael Hellwig and Kai Hüschelrath

Download this ZEW Discussion Paper from our ftp server:

http://ftp.zew.de/pub/zew-docs/dp/dp16063.pdf

Die Discussion Papers dienen einer möglichst schnellen Verbreitung von neueren Forschungsarbeiten des ZEW. Die Beiträge liegen in alleiniger Verantwortung der Autoren und stellen nicht notwendigerweise die Meinung des ZEW dar.

Discussion Papers are intended to make results of ZEW research promptly available to other economists in order to encourage discussion and suggestions for revisions. The authors are solely responsible for the contents which do not necessarily represent the opinion of the ZEW. 


\title{
CARTEl CASES AND THE CARTEL ENFORCEMENT PROCESS IN THE EUROPEAN UNION 2001-2015: A QuANTITATIVE ASSESSMENT
}

\author{
Michael Hellwig* and Kai Hüschelrath*
}

September 2016

\begin{abstract}
We provide a comprehensive quantitative assessment of cartels and the related cartel enforcement process in the European Union (EU) from 2001 to 2015. In a first step, we present a detailed characterization of all cartel cases decided by the European Commission (EC) with respect to various criteria such as the number of involved firm groups, cartel market shares and market share asymmetries, involved industries, affected countries, types of infringement, types of cartel breakdown as well as cartel duration. In a second step, we complement this cartel-based analysis with a quantitative assessment of the public cartel enforcement process in the European Union - subdivided further into its duration, types of cartel detection, the leniency program, the settlement procedure, overall fines imposed, and the conclusive appeals process with the General Court (GC) and the European Court of Justice (ECJ).
\end{abstract}

JEL Class K21, L41

Keywords Competition Policy, Cartels, Collusion, Enforcement, European Union

* ZEW Centre for European Economic Research and MaCCI Mannheim Centre for Competition and Innovation, Address: P.O. Box 1034 43, D-68034 Mannheim, Germany, E-mail: hellwig@zew.de.

* ZEW Centre for European Economic Research and MaCCI Mannheim Centre for Competition and Innovation, Address: P.O. Box 1034 43, D-68034 Mannheim, Germany, E-mail: hueschelrath@zew.de; University of Mannheim, L7, 3-5, 68131 Mannheim, Germany; Corresponding author. The paper makes use of ZEW's database on all EU cartel cases decided between 2001 and 2015. Since its inception in 2011, the database construction project profited from valuable contributions of several colleagues and we would like to thank Kathrin Schopen, Florian Smuda and especially Ulrich Laitenberger for their dedication and support. Furthermore, we are grateful to Bettina Chlond, Dominic Cucic, Amery Gülker, Lukas Maier, Bastian Sattelberger, Anne Zirngiebl and especially Cung Truong Hoang for excellent research assistance over the last few years. 
"Fighting cartels is one of the most important areas of activity of any competition authority and a clear priority of the Commission. Cartels are cancers on the open market economy, which forms the very basis of our Community. By destroying competition, they cause serious harm to our economies and consumers. In the long run cartels also undermine the competitiveness of the industry involved, because they eliminate the pressure from competition to innovate and achieve cost efficiencies."

Mario Monti, European Commissioner for Competition (1999-2004) ${ }^{1}$

\section{Introduction}

Among the few things most economists would likely agree on is the social harmfulness of cartels. Defined as "... group of firms who have agreed explicitly among themselves to coordinate their activities in order to raise market price ..."2 , a perfectly functioning cartel involving all firms in the market and referring to substitute products - is expected to not only cause static losses in consumer and overall welfare due to elevated monopoly prices but is also likely to generate dynamic inefficiencies in the form of, e.g., reduced incentives for product or process innovations ... or as Sir John Hicks once put it: “The best of all monopoly profits is a quiet life”3.

As cartels - in contrast to mergers - usually do not create any kind of benefits to society which could be traded-off against the anticompetitive effects, they are a prime example for a per se prohibition reflected in many antitrust legislations around the world - and with the European Union (EU) being no exception. At the latest since the tenure of Mario Monti from 1999 to 2004, all European Commissioners for Competition have clearly committed to the fight against cartels as top priority in European competition policy. While Neelie Kroes (2004-2010) reiterated that one of her key objectives was not only to “... merely destabilize cartels. I want to tear the ground from under them" ${ }^{4}$, her successor, Joaquin Almunia (20102014), reinforced the adamant stance: "The Commission will continue its relentless fight against cartels" 5 .

Consistent with these clear general statements of former Commissioners on the importance of the fight against cartels, the European Commission (EC) was very active in both refining

1 Speech on "Fighting Cartels Why and How? Why Should we be Concerned with Cartels and Collusive Behaviour?” at the 3rd Nordic Competition Policy Conference, Stockholm, 11 September 2000, SPEECH/00/295.

2 Pepall et al. (1999), p. 345.

3 Hicks (1935), p. 8.

4 Speech on "Tackling Cartels - A Never-Ending Task" at an Anti-Cartel Enforcement: Criminal and Administrative Policy Panel Session, Brasilia, 8 October 2009, SPEECH/09/454.

5 Speech on "First Cartel Decision under Settlement Procedure - Introductory Remarks" at the European Commission, Brussels, 19 May 2010, SPEECH/10/247. 
and extending EU cartel policy tools. In particular, since the beginning of the new century, the Commission implemented two revisions of the leniency program, completed a major reform of the fine guidelines, introduced a settlement procedure, intensified cooperation between competition authorities in the fight against particularly international cartels and - finally yet importantly - promoted the private enforcement of anti-cartel laws.

From an academic perspective, the identified policy changes together with the availability of detailed cartel- or even firm-specific data - published by the Commission, the General Court and the European Court of Justice as part of their respective decisions or judgments provide an ideal environment for conducting quantitative research. However, while both a significant number of specific econometric studies ${ }^{6}$ - e.g., evaluating the Commission's leniency policy or investigating the determinants of cartel duration - as well as more surveytype assessments ${ }^{7}$ exist, a comprehensive quantitative assessment of both detected cartels as well as the cartel enforcement process in light of the recent policy changes is currently missing. Although such studies admittedly face the usual disadvantages attached to the use of descriptive empirical analysis, they have the key advantage of being able to provide a full picture on cartel cases and the enforcement process thus promising to generate substantial value for both academic and practical purposes.

In this context, we provide such a comprehensive quantitative assessment of detected and decided cartels and the related cartel enforcement process in the European Union from 2001 to 2015 - with the remainder of the paper being structured as follows. Section 2 provides a general initial characterization of cartels and cartel enforcement in the European Union. In parallel to a description of the entire cartel enforcement process, the section also introduces into the major changes in EU cartel rules and policies. Furthermore, a description of our database on EU cartel cases is provided.

Section 3 then continues with a detailed characterization of all cartel cases decided by the European Commission between 2001 and 2015 with respect to various criteria such as the number of involved firm groups, cartel market shares and market share asymmetries, involved

6 Aiming at increasing the readability of the paper, we refrain from providing reviews of the rather large theoretical and empirical literature on cartels and cartel policies in various jurisdictions (see, e.g., Carree et al. (2010) or Hüschelrath and Weigand (2013) for detailed assessments).

7 To the best of our knowledge, a comprehensive quantitative assessment of EU cartels and the cartel enforcement process does not exist. Harrington (2006) also makes use of the detailed cartel case information provided by the Commission to study how competitors manage to implement and stabilize cartel agreements. Veljanovski $(2007,2011)$ and Wils (2002) provide detailed assessments of particularly the fining policy of the European Commission in light of the introduction of the 1998 fine guidelines. Finally yet importantly, Carree et al. (2010) and Russo et al. (2010) provide detailed assessments of European Commission decisions on competition including cartel agreements. However, both studies do not provide a complete quantitative assessment of EU cartel cases and the cartel enforcement process and make use of a data set that ends in 2004 (thus preventing an investigation of the effects of the EU cartel policy changes in the new century). 
industries, affected countries, types of infringement, types of cartel breakdown as well as cartel duration. In Section 4, we complement this cartel-based analysis with a quantitative assessment of the cartel enforcement process in the European Union, subdivided further into its duration, types of cartel detection, fines levels, the leniency program, the settlement procedure and the conclusive appeals process with the General Court (GC) and the European Court of Justice (ECJ). Section 5 closes the paper with a discussion of its main insights and an identification of avenues for future research.

\section{Cartels and cartel enforcement in the European Union: An initial characterization}

In this section, we provide an initial high-level characterization of public cartel enforcement ${ }^{8}$ in the European Union. In parallel to the description of the entire enforcement process in the subsequent subsection, we briefly introduce the four major changes in EU cartel rules and policies in our observation period from 2001 to 2015: (1 and 2) the revisions of the leniency program in 2002 and 2006 (originally introduced in 1996), (3) the revision of the fine guidelines in 2006 (originally introduced in 1998), and (4) the introduction of the settlement procedure in 2008. The section is closed by a description of our database of EU cartel cases which provides the basis for our quantitative assessment of EU cartel cases and EU cartel enforcement in Sections 3 and 4.

\subsection{The cartel enforcement process in the European Union}

Article 101 of the Treaty for the Functioning of the European Union (TFEU) prohibits agreements between companies which prevent, restrict or distort competition in the EU and which may affect trade between Member States. Although the prohibition generally applies to both (anti-competitive) horizontal and vertical agreements, in the following, we will focus on a brief characterization of the EU enforcement process for horizontal 'hard-core' cartel agreements, which can broadly be subdivided further into (1) the investigation and decision by the European Commission and (2) the (optional) initiation of an appeal against the respective EC cartel decision by one or more of the convicted cartel members. ${ }^{9}$

\footnotetext{
8 In this paper, we concentrate on the public enforcement of anti-cartel laws in the European Union. See, e.g., Hüschelrath and Peyer (2013) for a law and economics perspective on the private enforcement of anti-cartel laws and its interaction with public enforcement.

9 The description of the EU cartel enforcement process largely follows European Commission (2013), Competition: Antitrust Procedures in Anticompetitive Agreements, Brussels, available at http://ec.europa.eu/ competition/publications/factsheets/antitrust_procedures_101_en.pdf (last accessed on 10 August 2016) and additional sources mentioned in Hellwig et al. (2016).
} 
Investigation and decision by the European Commission

In general, the cartel enforcement process within the EC can be subdivided further into six subsequent stages: (1) initial information gathering, (2) preliminary investigations, (3) case proceedings, (4) statement of objections, (5) oral hearings and (6) decision. As cartel members are typically aware of the fact that their agreements are illegal, they keep them in secrecy and initial information gathering therefore becomes the most crucial step in the enforcement activities of the EC. While a complaint by a competitor, a customer, another agency or a (former) employee used to be the dominant way to initiate cartel investigations, the importance of the leniency program as case generator began to rise with its introduction in 1996 and two subsequent reforms of the program in 2002 and 2006. Generally, a leniency program (LP) offers law infringers either a fine reduction of even full amnesty if they disclose an infringement to the responsible authority and (fully) cooperate with it during the investigation.

Subsequent to the initial gathering of information on an alleged cartel infringement, the EC can decide to open preliminary proceedings as part of which it can use certain investigative powers such as, e.g., dawn raids or other information requests to be able to assess whether the rules laid down in Article 101 TFEU have been breached. At the end of the preliminary proceedings, the EC has to make a decision whether the collected material appears sufficient to initiate case proceedings - and therefore an in-depth investigation - or alternatively to close the investigation.

In case an in-depth investigation is commenced and results in the confirmation of the EC's initial concerns, the EC furnishes a statement of objections (SO) in which it - based on the collected pieces of evidence - informs the respective firms in writing of the objections raised against them. After the submission of the SO to the accused firms, they have certain rights to defense such as 'access to file', i.e., they are allowed to see all non-confidential pieces of evidence collected by the EC during its investigation. Subsequently, the parties have the right to reply to the SO in writing and to request an oral hearing with an independent hearing officer. Interestingly, since the introduction of the settlement procedure in 2008, the Commission has the possibility to bypass these time-consuming procedural steps by offering a settlement to the involved parties. In exchange for their admittance of liability, the Commission grants a fine reduction of 10 percent and is expected to reach a significant reduction in the duration of the respective proceedings.

In non-settled cases - after reconsidering its own analysis and results in light of the feedback of the accused firms - the EC may decide to abandon (part of) its initial objections 
(or even to close the case). If the EC's concerns are not fully dispelled, it drafts a decision prohibiting the respective infringement. The draft decision is then submitted to the Advisory Committee (composed of representatives of the Member States' competition authorities) for a final check. If fines are proposed in the draft decision - as usually the case in cartel investigations - the Committee meets a second time to specifically discuss them before the draft decision is submitted to the College of Commissioners which adopts the decision.

The fine level imposed by the European Commission on the respective cartel members is the key output of the entire cartel investigation and decision process. By imposing fines, the European Commission pursues two interrelated goals: punishing detected breaches of competition law and deterring future infringements. Aiming at implementing both goals in a transparent and effective fashion, the EC introduced first 'Guidelines on the method of setting fines' in 1998 that were revised substantially in 2006.

The appeals process against decisions by the European Commission

As any decision by either a court or a public authority is made under uncertainty, it is considered a constitutional right of the losing party to seek a reconsideration of their arguments as part of an appeals (or judicial review) process. Under EU competition law in general, and for EC cartel cases in particular, the appellate court proceedings can be either one- or two-stage. At the first stage, a cartel member that has serious concerns with a (fining) decision of the EC can file an appeal with the General Court (GC) of the European Union. Generally, the GC not only has the power to annul, reduce or increase the fines imposed by the EC, it also has full jurisdiction to review the entire Commission decision (including a repetition of the full assessment process).

At the second stage of the appeals process in EC cartel cases, judgments of the GC can be appealed before the European Court of Justice (ECJ) by the unsuccessful party, i.e., either the convicted firm, the EC itself or both. The ECJ is the highest European appellate court and has the power to annul, reduce or increase the fines imposed by the GC. However, in its proceedings, it limits itself to questions of law and has no jurisdiction to (re-)review the facts and analyze the evidence that the GC used to support its findings and decision.

\subsection{Description of the database of EU cartel cases from 2001 to 2015}

Before we commence with our quantitative assessment of cartel cases and the cartel enforcement process in the European Union between 2001 and 2015, is it is important to briefly describe the construction of our database. Back in 2011, ZEW started to construct a detailed database of all cartel cases decided by the European Commission since the year 2001 . 
The database was extended further and further and currently contains detailed information on all cartel indictment and appeals cases decided by the EC, the GC and the ECJ between 2001 and 2015. The data were collected from decisions and press releases published by the EC in the course of its investigations as well as from judgment documents provided by the online platform CVRIA.

In particular, the database combines cartel-related, firm group-related and firm-related information. At the cartel level, information such as the cartel type, cartel duration, number of cartel members, involved industry, relevant geographic market(s) and imposed overall fines are available. With a view to firm- and group-specific data, the database contains information on the individual length of cartel participation, the fine amounts imposed by the EC, whether the firm applied for leniency or appealed the EC decision and the value of fine reductions following a successful leniency application or appeal. Furthermore, specific factors that are relevant for the calculation of the fine, including aggravating and mitigating circumstances or repeat offenders, have been documented as well.

Although we believe to have created a uniquely rich database on European cartels, it is important to close with an important disclaimer when it comes to an interpretation of various breakdowns of the data presented in the following sections. By definition, our entire quantitative assessment is based on the population of detected cartels whose cases were decided by the European Commission between 2001 and 2015 (excluding three readopted cases $^{10}$ ). Although recent research by Harrington and Wei (2016) suggests that such a sample of detected cartels may tell us something about the latent universe of cartels, the fact that our quantitative analysis can only rely on the population of detected and decided cartels is certainly important to have in mind - particularly in attempts to provide a broader discussion of the implications of some of our main findings.

\section{Characterization of EU Cartel Cases decided between 2001 and 2015}

In this section, we present a detailed characterization of all cartel cases decided by the European Commission between 2001 and 2015. In particular, we subdivide our descriptive quantitative assessment into the following seven distinct topics: (1) number of cases, cartels and involved firm groups, (2) cartel market shares and market share asymmetries, (3) involved industries, (4) affected countries, (5) types of infringement, (6) types of cartel breakdown as well as (7) cartel duration. In the corresponding seven subsections, we commence by providing the respective absolute numbers for both the entire observation

10 The cases are Gas Insulated Switchgear (Case COMP/39.966), Steel Beams (Case COMP/38.907) and Manufacture of other Organic Basic Chemicals (Case COMP/39.003). 
period - i.e., 2001 to 2015 - and three subperiods with a length of five years each - i.e., 2001 to 2005, 2006 to 2010, and 2011 to 2015 - followed by a more detailed assessment of selected developments over time by mostly comparing relative figures on a yearly basis.

\subsection{Number of cases, cartels and involved firm groups}

A natural starting point for a characterization of detected EU cartels is a detailed discussion of the number of cases, cartels and involved firm groups. While the number of decided cases essentially is a measure of the yearly enforcement activity of the European Commission - to the degree that this is reflected in the closing of a case with a certain case number - the number of cartels diverges as soon as the Commission decides to investigate separate (but still related) cartels under a single case number. ${ }^{11}$

In contrast to the number of cases and cartels as key enforcement variables, the number of involved firm groups ${ }^{12}$ is an important internal characteristic of the detected cartels. Ceteris paribus, it can be expected that reaching and sustaining a cartel agreement becomes more and more complicated with an increasing number of firms - basically because they are likely to all have diverging plans and interests on an appropriate design and implementation of the cartel agreement.

Based on this categorization, an initial summary of our data reveals that over the entire observation period from 2001 to 2015, in sum 90 cases were decided by the European Commission, consisting of 113 cartels and 600 involved firm groups. The distribution of these values over the respective years is shown in the two charts in Figure 1.
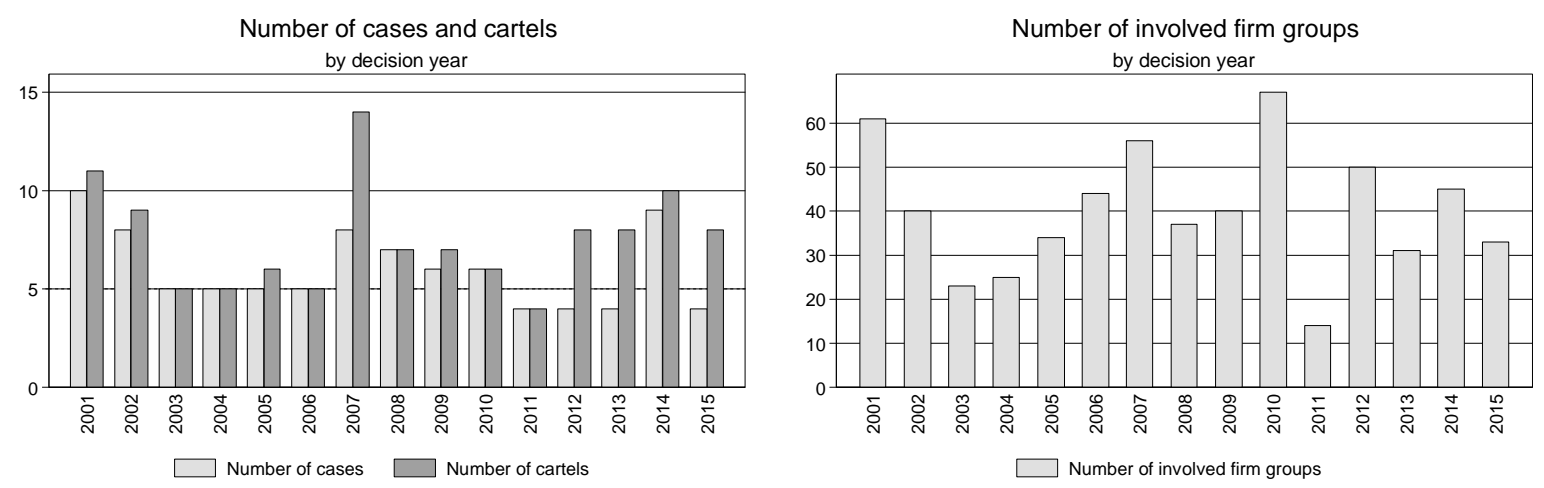

Figure 1: Number of cases, cartels and involved firm groups Source: own figure based on ZEW cartel database

11 In order to account for this disparity, we speak of 'decided cases' when referring to the European Commission's decisions and of 'cartel cases' when referring to the underlying cartels.

12 Groups of firms were formed according to the respective EC decisions, i.e., firms within a group are linked through ownership and are jointly liable for cartel fines. 
Starting a discussion of Figure 1 with the number of decided cases plotted in the left-hand chart, it is shown that - in our observation period from 2001 to 2015 - between 4 and 10 cases were decided by the European Commission per year, leading to a total average of almost 6 cases per year. However, subdividing our observation period into three five-year subperiods reveals a certain downward trend in the number of cases from on average 6.6 cases in the 2001-2005 period, via 6.4 cases in the $2006-2010$ period to 5.0 cases in the final $2011-2015$ period.

Furthermore, although the number of cartels is - as expected - found to be related to the number of cases, both categories only show identical values in 6 out of the 15 years which define our observation period. While the total average is about 7.5 cartels per year, again applying the three five-year subperiods show an increase in the number of cartels from 7.2 cases in the 2001-2005 period, via 7.8 cases in the 2006-2010 period to 7.6 cases in the most recent 2011-2015 period. In other words, the observed downward trend in the number of cases cannot be found when focusing on the number of cartels. Although admittedly speculative, changes in both the structure of cartels and/or the organization of work within the Commission might explain the recent increase in the bundling of several related cartels into a single case.

In addition to the number of cases and cartels, the right-hand chart in Figure 1 above shows the yearly developments of the number of involved firm groups. Interestingly, the respective yearly values are found to fluctuate quite substantially between the lowest value of 14 involved firm groups in 2011 and the highest value of 67 involved firm groups in 2010. While the first period from 2001 to 2005 experienced an average number of involved firm groups of about 37, the value increased to about 49 in the 2006-2010 period; however, subsequently experiencing a drop to about 35 firm groups in the final period from 2011 to $2015 .^{13}$

Complementary to information on the absolute numbers of the involved firm groups, the above mentioned expected relationship between the number of firms in an industry/cartel and the likelihood of cartelization suggests a brief assessment of the average number of involved firm groups per cartel. The respective values are presented in Figure 2.

13 However, the fact that the lowest and highest values appeared in subsequent years - but were allocated to different subperiods - suggests that the respective averages of these two subperiods are strongly biased making any additional interpretation of the values obsolete. For example, if the observation period is subdivided into two periods - 2001 to 2008 and 2009 to 2015, the respective average values for the number of involved firm groups are found to be almost identical at 40 firm groups in both subperiods. 


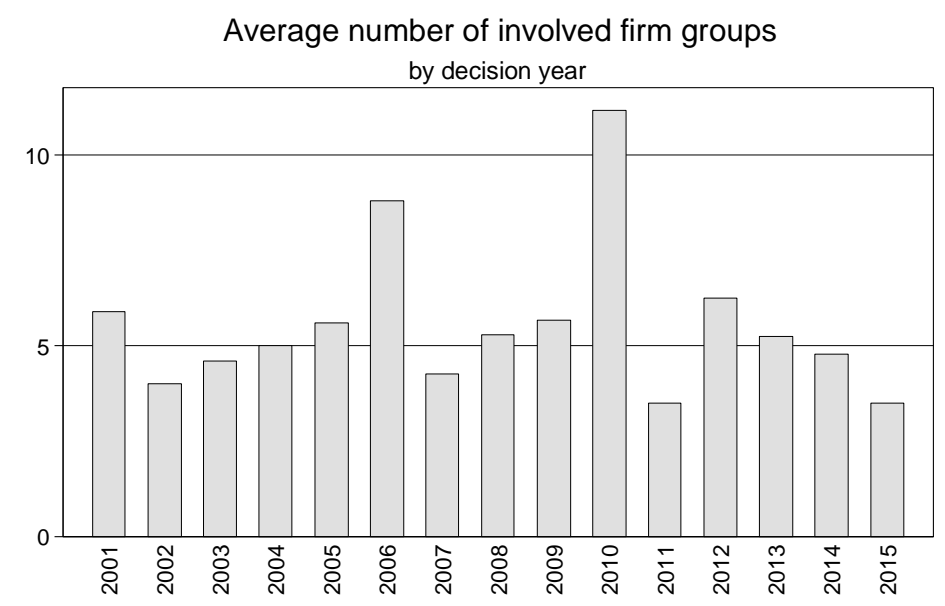

Figure 2: Average number of involved firm groups

Source: own figure based on ZEW cartel database

As shown in Figure 2, with the two exceptions of the years 2006 and 2010, the average number of involved firm groups fluctuates around an average of 5.6 firm groups per cartel over the entire observation period. However, while the first enforcement period from 2001 to 2005 shows only limited variation around an average of 5.0 firm groups, the average of 7.0 firm groups for the subsequent 2006 to 2010 period includes the two extreme values making a direct comparison less insightful. ${ }^{14}$ The last period from 2011 to 2015, however, is then characterized by a clear decrease in the average number of involved firm groups reflected in an average value of 4.7 firm groups.

Before we turn to a further characterization of the cartel cases decided by the European Commission between 2001 and 2015, it is important to introduce a general differentiation in the presentation of cartel statistics. So far, we have analyzed the respective cases, cartels and involved firm groups by using the year of decision by the European Commission as basis. Although such a breakdown of the data appears appropriate in a quantitative assessment of most cartel enforcement characteristics, two alternative bases may occasionally produce better interpretable (and more insightful) results: the year of cartel detection and the year of cartel cessation.

For example, if the aim is to assess different types of cartel breakdown (e.g., natural death or detected by the Commission while ongoing) - including the study of possible linkages between cartel breakdowns and cartel policy changes (such as, e.g., the introduction or reform

14 Please note that the two years with an unusually high average number of involved firm groups are followed by years with unusually low average numbers (i.e., 2007 and 2011) suggesting that the differences might simply be driven by 'end of year' effects. For example, whether a larger case is decided in December or January can have a substantial influence on overall yearly statistics (due to the generally rather low absolute numbers of cases, cartels, and involved firm groups). 
of a leniency program) - an analysis based on the decision date may provide only limited (biased) insights; basically because the inceptions and durations of EC case investigations typically diverge quite substantially. Furthermore, although an analysis based on the year of detection is likely to provide more valuable information, a quantitative analysis based on the year of cartel cessation will generate further insights - especially in light of the fact that roughly half of the cartels in our database died of natural causes while the other half was detected by the European Commission at a later point in time.

Aiming at further substantiating our claim that the choice of the most suitable basis for the question at hand can be crucial, Figure 3 below shows the number of cartels for the three different bases just introduced: year of cartel cessation, year of detection and year of decision.

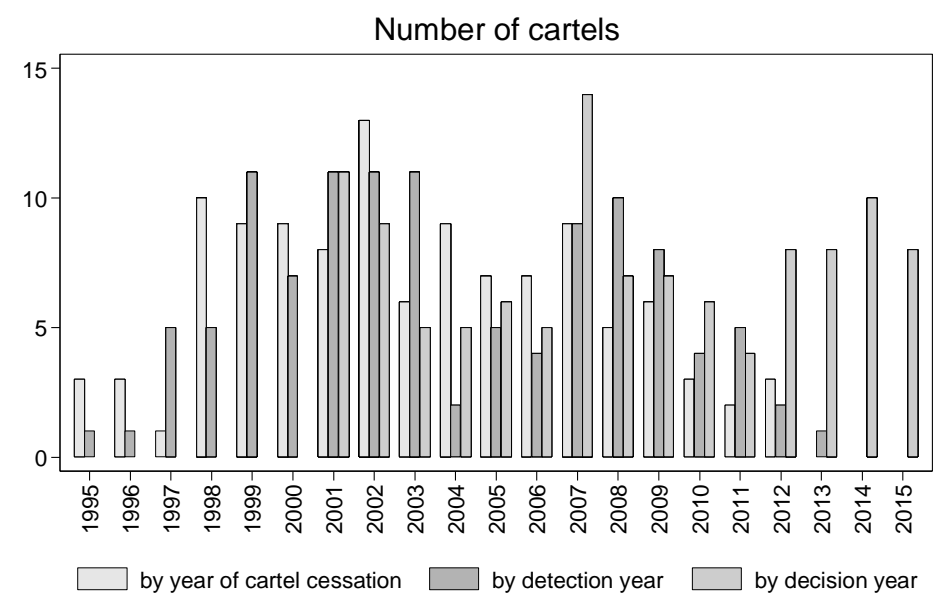

Figure 3: Number of cartels by year of cartel cessation, detection and decision Source: own figure based on ZEW cartel database

As shown by Figure 3, the three alternative bases of measuring the number of cartels reveal partly substantial differences. Attempting to disentangle the underlying drivers, it becomes obvious that - although Figure 3 still refers to all EU cartel cases decided between 2001 and 2015 - the 'year of cartel cessation' basis demands an extension of the time scale down to the year 1995 - as the oldest 3 cartels that were decided in the 2001-2015 observation period ceased to exist already in 1995. At the other end of the observation period, Figure 3 further shows that 3 cartels that ended in 2012 were already decided by the European Commission until the end of 2015.

For the 'year of detection' basis, Figure 3 reveals that the first cartels decided on in our observation period from 2001 to 2015 were already detected in the mid to late 1990’s - e.g., 1 cartel each in 1995 and 1996 and even 5 cartels in 1997 - reflecting the rather long duration of an investigation by the European Commission. Furthermore, Figure 3 also shows that the youngest cartel that was already decided on - until the end of the year 2015 - was detected in 
2013. However, again taking the average duration of cartel case investigations into account, it is highly likely that further cartels that were detected, e.g., in 2013, will be decided by the European Commission in the years to come. As a consequence, especially the values on the right-hand side of Figure 3 are expected to change in case the observation period is extended beyond the year 2015 .

\subsection{Cartel market shares and market share asymmetries}

While the previous section discussed the absolute and average numbers of firm groups involved in cartel agreements detected by the European Commission, we now turn to an assessment of the respective market shares of the cartels in general and market share asymmetries between cartel members in particular. Both characteristics have direct relationships to the theory of cartelization. First, the possibilities and incentives to form a cartel are expected to increase with the aggregated market share of the cartel - basically because it increases the significance and therefore the profits of the cartel. Vice versa, an increasing share of non-cartel members ('cartel outsiders') reduce the possibilities and incentives to form a cartel as the overall cartel profit's pie - as well as the individual slices for the separate cartel members - are likely to shrink.

Second, in addition to the scope of the cartel agreement as such, the asymmetry of market shares between the cartel members is a further characteristic that may influence the likelihood of cartelization as well as the stability of such agreements. Ceteris paribus, it is reasonable to expect that it is easier to reach and maintain an agreement between four firms that all have identical market shares compared to more asymmetric situations in which, e.g., one firm has a substantially larger market share than the other cartel members.

Aiming at investigating both characteristics for the 113 cartel cases in our database, it is important to remark that the respective information is only available for smaller subsets of our database. While detailed information on combined market shares was available for in sum 51 cartel cases, the sample was reduced further to in sum 40 cartels for which the market shares of all members were either directly reported in the Commission's decision documents or calculated by using available case information. ${ }^{15}$ Figure 3 below shows the respective combined market shares of the cartel and all cartel outsiders (ordered by decision date).

15 It should be noted further that the cases for which the respective information was available are not equally distributed over time. The very large majority of included cases was decided in either the first (2001-2005) or the second (2006-2010) subperiod. 


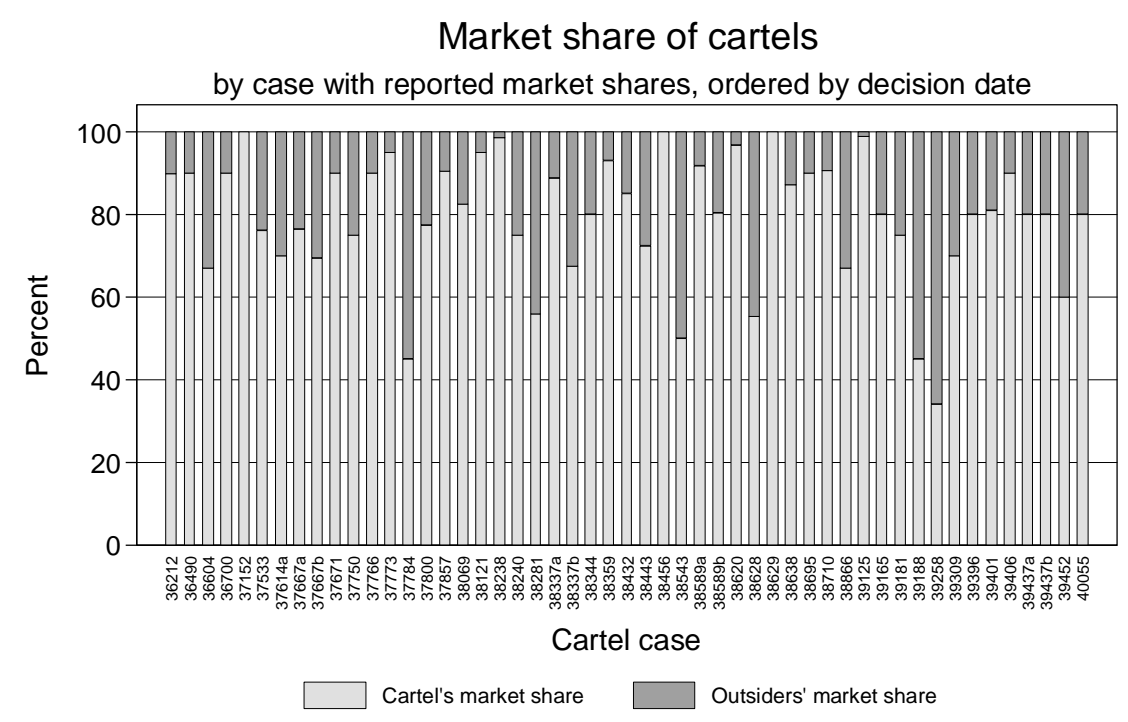

Figure 4: Market share of cartel and non-cartel members Source: own figure based on ZEW cartel database

As shown by Figure 4, the combined market share of all cartel members in the respective cartels is rather high, reaching an average of 79 percent for all 51 cases for which the respective information was available. However, in only 3 cases, the cartel was complete in the sense that it included all firms operating in the respective market - suggesting that the large majority of cartels have to somehow cope with the presence of (a) cartel outsider(s). Furthermore, in 3 different cartels ${ }^{16}$, the combined market shares of all members were rather low reaching values below 50 percent. However, in all these cases, certain specificities of the industry and cartel led to successful cartelization despite rather low combined market shares.

Turning from an assessment of combined market shares to the more specific question of the degree of asymmetry in the market shares of the respective cartel members, (at least) two separate measures can be differentiated. First, the respective market shares of the cartel members (in percentage values) can simply be plotted allowing the identification of different degrees of market share asymmetry. Second, a Herfindahl-Hirschman Index (HHI) for the market shares of all cartel members can be calculated. As the HHI, by definition, takes both the sizes of the individual market shares as well as the distribution of the different individual market shares into account, such a cartel-related $\mathrm{HHI}^{17}$ can be seen as a useful additional

16 The respective three (specific) cases are Fine Art Auction Houses (Case COMP/37.784), Bananas (Case COMP/39.188) and Airfreight (Case COMP/39.258).

17 The cartel-related HHI is defined as the sum of the squared market shares of all cartel members, i.e., the rest of the market in the form of potential cartel outsiders is ignored. By construction, the HHI not only rises with a general increase in concentration but also with an increasing asymmetry of the market shares. For example, if a cartel consists of four members having a market share of 20 percent each, the respective cartel-related HHI can be derived as follows: $\left[(0.2)^{2}+(0.2)^{2}+(0.2)^{2}+(0.2)^{2}\right]^{*} 10,000=1,600$. However, assuming a more 
measure. In Figure 5 below, we combine both measures to facilitate an easier comparison and interpretation.

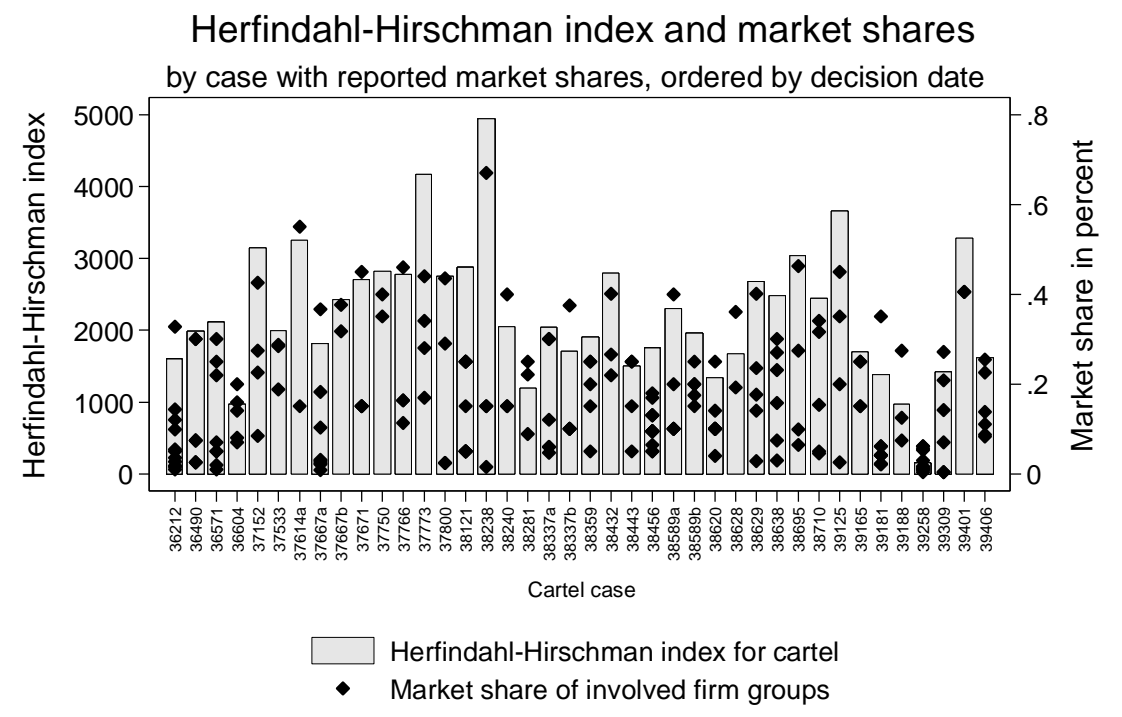

\section{Figure 5: Herfindahl-Hirschman Index and market share distribution of firm groups Source: own figure based on ZEW cartel database}

Starting with an interpretation of the HHI values plotted in Figure 5, it is revealed that although the majority of cartels reach values above 1,800 - thus suggesting an at least moderately concentrated market - the variation between the different cartels is rather large. While the average HHI value for all cartel cases shown in Figure 5 is found to be 2,114, the spectrum of HHI values reaches from 153 in the Airfreight case (Case COMP/39.258) characterized by cartel members with exclusively small market shares - to 4,942 in the Raw Tobacco Spain case (Case COMP/38.238) - characterized by one dominant cartel member with a market share of 67 percent, two further cartel members with a market share of 15 percent and a fourth member with a share of 1.6 percent.

Additionally, the individual market shares of the involved firm groups - represented by the respective black rhombuses on the respective HHI bars - reveal that cases with a low cartel HHI are indeed characterized by a few rather small cartel members who were - due to the above mentioned industry- and cartel-specifics - still able to successfully form a functioning cartel. For example, in the Airfreight case, a group of larger airlines - mostly operating in passenger transportation but also using the belly of airplanes for freight transportation coordinated on prices for airfreight (and partly also various surcharges). As the airfreight business also includes large specialized companies - who mostly did not participate in the

asymmetric allocation of cartel-related market shares, e.g., 40 percent, 20 percent, 10 percent and 10 percent would result in an cartel-related HHI of 2,200 (i.e., a higher concentrated and more asymmetric market). 
cartel - and the respective market shares also vary substantially between the various global transportation routes, an untypically small combined market share or about 34 percent was identified by the Commission ${ }^{18}$ - leading to the unusually small cartel-related HHI value mentioned above.

\subsection{Involved industries}

A further variable of interest in the characterization of EU cartel cases relates to the involved industries. As the possibilities for successful cartelization are influenced by various characteristics of the respective industries - to mention the size of entry barriers, the frequency of interaction, the degree of market transparency or business cycle similarities as prominent examples - absolute and relative information on the involved industries are helpful in identifying industries particularly prone to collusion (probably suggesting targeted further detection activities by the competition authority or the respective firms themselves).

In absolute terms and over the entire observation period from 2001 to 2015, our quantitative assessment reveals that the large majority of 89 out of the in sum 113 cartel cases (i.e., about 79 percent) took place in manufacturing, followed by 8 cartels in transportation and storage and 6 cartels in financial and insurance activities. The remaining 10 cartels are distributed over the remaining industries as follows: 3 cartels in agriculture, forestry and fishing as well as in wholesale and retail trade, 2 cartels in electricity, gas, steam and air conditioning supply and finally 1 cartel in the categories construction and arts, entertainment and recreation, respectively. In relative terms, Figure 6 shows the development of the respective yearly shares for the entire observation period from 2001 to 2015.

18 Interestingly, in December 2015, an appeal of several airlines against the Commission decision with the General Court was successful - partly due to the unclear determination of the nature and scope of the agreement fined by the Commission. See General Court of the European Union, "The General Court annuls the decision by which the Commission imposed fines amounting to approximately $€ 790$ million on several airlines for their participation in a cartel on the air freight market”, Press Release No 14 7/15, Luxembourg, 16 December 2015. 


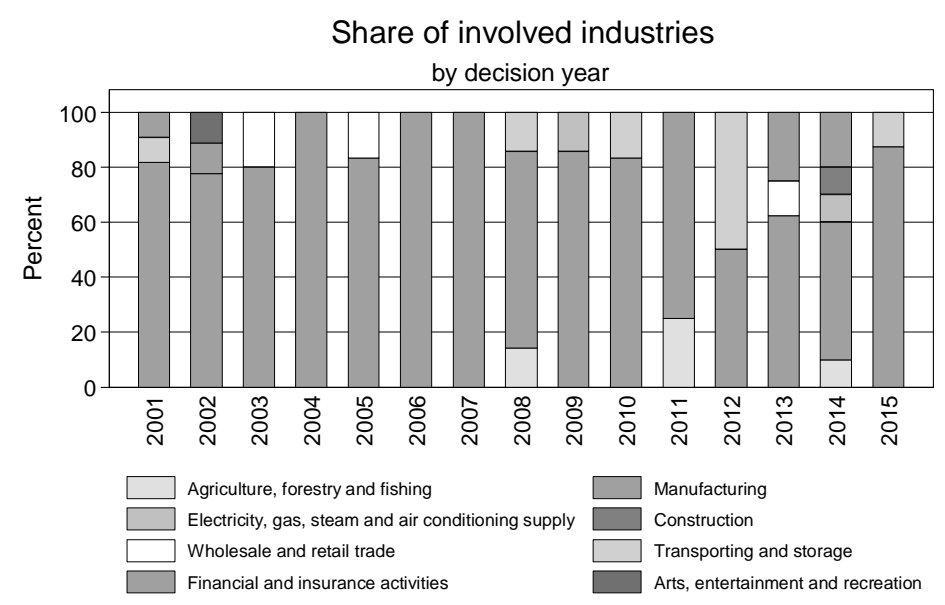

Figure 6: Share of industries involved in cartelization

Source: own figure based on ZEW cartel database

Due to large absolute number of cartel cases in manufacturing, it does not come as a surprise that this industry is also dominant in terms of yearly shares. While the lowest share of 50 percent of all cases was reached in 2012, the years 2004, 2006 and 2007 exclusively had cases from the manufacturing industry. The observations for all other industries are essentially too small and erratic to allow an insightful interpretation of particular patterns.

\subsection{Affected countries}

In addition to the involved industries, the countries affected by cartel agreements provide further interesting insights for at least three reasons. First, again referring to cartel theory, it appears, ceteris paribus, more challenging to form and stabilize a cartel agreement with firms stemming from a larger number of different countries; for example, as the respective firms might not only have different expectations and mentalities or speak different languages (leading to a more difficult and possibly error-prone communication) but also because they might face different economic situations in their home countries (possibly leading to different deviation incentives). Second, information on the number of affected countries allow an investigation of the often raised claim that cartels have become more and more international in the last one or two decades. Third, general information on the number of involved firm groups per country gives away at least some information on the respective competition climate and the functioning of the respective competition policy regimes.

Starting our characterization of the affected countries with some absolute numbers for our entire observation period from 2001 to 2015, Figure 7 shows all countries involved into at least one cartel case and the respective absolute number of involved firms per country. 


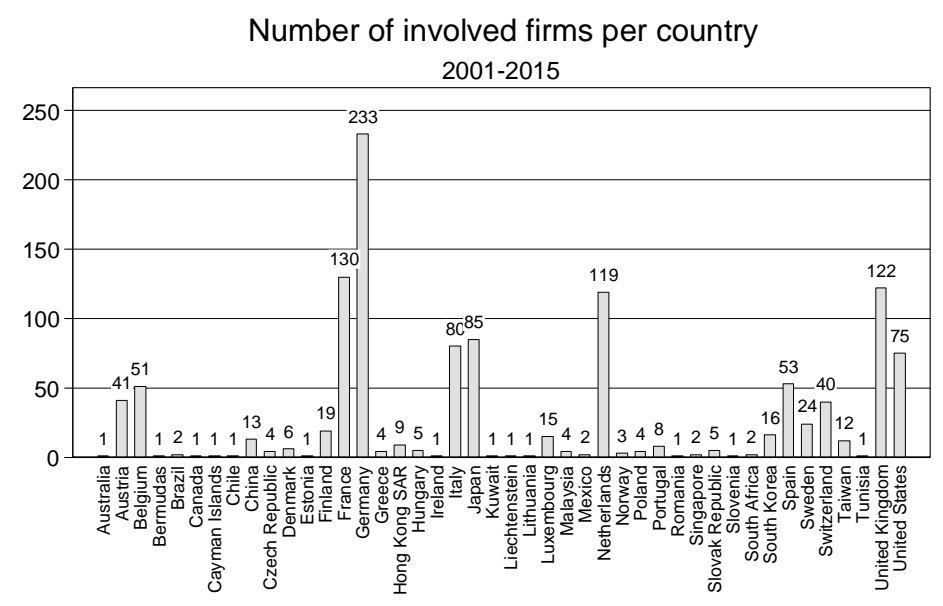

Figure 7: Number of involved firms per country

Source: own figure based on ZEW cartel database

As revealed by Figure 7, while only 44 out of a total of 194 countries worldwide were involved in at least one cartel case with the European Commission, consulting the ranking of the 20 largest economies in the world (by nominal IMF GDP data) reveals that only India, Russia, Indonesia, Turkey and Saudi Arabia were not involved in any of the cartel cases decided by the Commission between 2001 and 2015.

Furthermore, as further shown by Figure 7, in sum 233 German firms were involved in EU cartel decisions in the observation period from 2001 to 2015 with France (130 firms), the United Kingdom (122 firms) and the Netherlands (119 firms) being the runner-ups. In sum, the firms out of these four economically large European countries alone represent about 50 percent of all firms involved in one or more EU cartel cases. ${ }^{19}$

Complementary to the presentation and discussion of absolute values, an analysis of relative values over time is likely to generate additional insights. Figure 8 below therefore plots the respective percentage shares by decision year for the following five geographical regions (1) Northern Europe, (2) Southern Europe, (3) Western Europe, (4) Eastern Europe and (5) Non-Europe.

19 Please note that the respective firm groups are counted on a case-basis, i.e., if companies were involved, e.g., two or three times as part of different cartels, they also appear in the respective statistics - plotted in Figure 7 above - two or three times. However, even without double-counting, Germany would still be at the top of the list with 192 involved firms. 


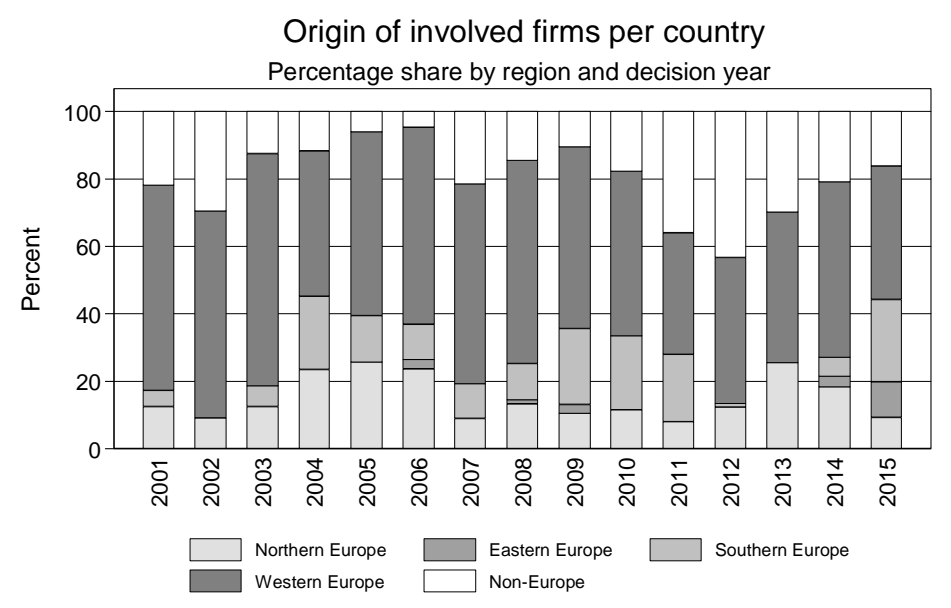

Figure 8: Origin of involved firms per country

Source: own figure based on ZEW cartel database

As shown in Figure 8, Western Europe has - in all years of the observation period - the highest shares spanning a range from 36 percent in 2011 to 69 percent in 2003. While at least one of the Southern European countries were involved in one or more cartels in most of the years of the observation period, the rather small presence of Eastern European countries mostly concentrates on the second half of the observation period. Interestingly, participation of Non-European cartel members appears to follow a wave pattern with significant shares towards the beginning of the observation period, however, then followed by a substantial reduction of the respective share. While the years 2010 to 2012 experienced again a substantial share increase - reaching the highest value of 43 percent in 2012 - the last three years again show a reduced share of Non-European firms out of the entire group of cartel members.

Complementary to a discussion of absolute and relative values with respect to the number of affected countries, it adds value to study the average number of countries in a cartel. Figure 9 provides the respective information based on the decision year. The documented clear increase in the average number of countries in a cartel in the first few years of the new century supports the above view of an increasing share of international cartels. However, as also shown in Figure 9, after reaching the peak in 2010, the subsequent years show a declining trend in the average number of countries in a cartel. 


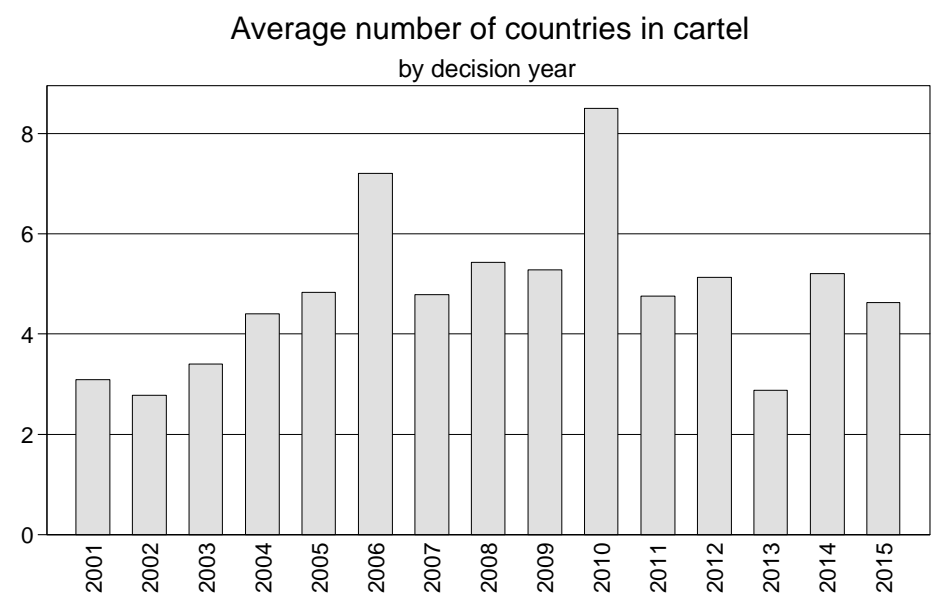

Figure 9: Average number of countries in a cartel

Source: own figure based on ZEW cartel database

Although we are unable to substantiate this descriptive finding any further in the remainder of this paper, two developments may have driven the observed trends. On the one hand, the detection of more and more international cartels reflects the increased cooperation efforts by competition authorities within the European Union - first and foremost through the European Competition Network (ECN) - but also worldwide though (less formal) cooperation efforts as part of the International Competition Network (ICN). On the other hand, the increasing number of involved countries might also be explained by an increased pace in the globalization of markets in earlier years that led to an increased desire to reduce or even eliminate the rising international competitive pressures through cartel agreements.

\subsection{Types of infringement}

In the industrial organization textbook by Pepall et al. (1999, p. 345), a cartel is defined as a “... group of firms who have agreed explicitly among themselves to coordinate their activities in order to raise market price ...”. Consequently, all types of explicit agreements among direct competitors that are expected to raise market price are considered as explicit (and therefore illegal) cartel. Although this definition certainly includes the classical price-fixing agreement, it is not limited to it as also agreements on quantity fixing, market sharing, exchange of information or bid-rigging typically aim at increasing market price and are therefore also categorized as explicit cartel agreements.

Turning to the presentation of our quantitative findings, it is important to mention upfront that - although several cases exist in which only one clear type of infringement was implemented - the majority of cartels were found to operate with a mixture of two or more different types of infringement. This is clearly reflected in the absolute numbers for the entire 
observation period from 2001 to 2015 finding elements of direct price-fixing in 94 out of 113 cartel cases. Furthermore, while 62 cartels included some form of market sharing and 50 cartels contained some form of illegal exchange of information, only 26 cartels showed sufficient evidence for quantity fixing. Bid rigging evidence was found in only 4 cartels.

In relative terms, Figure 10 below provides further insights on a yearly basis. With only few exceptions in recent years, price-fixing appears as dominant form in the organization of a cartel with shares between 32 percent in 2015 and 67 percent in 2011 - based on the number of decided cartel cases in the respective years.

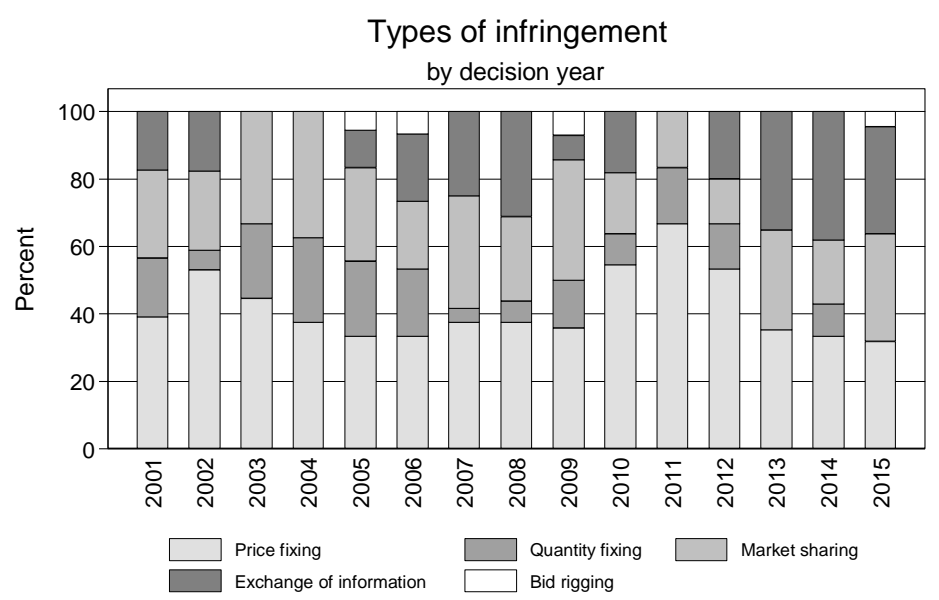

Figure 10: Types of infringement

Source: own figure based on ZEW cartel database

Interestingly, as also shown in Figure 10, the role of quantity fixing seem to erode over the observation period even disappearing entirely in 2013 and 2014. At the same time, cartels in which an exchange of information was involved gained in shares in recent years - even challenging the role of market sharing as the second most prominent type of infringement. One possible reason for this development could be seen in a certain closeness of this type of infringement to the (legal) alternative of tacit collusion, i.e. by applying such forms of explicit collusion, firms might hope to either avoid punishment or to at least complicate detection (in combination with a reduction in the severity of the infringement leading to lower fines).

\subsection{Types of cartel breakdown}

The type of cartel breakdown is a further characteristic of potential interest in studying EU cartel cases. Generally, two broad types of cartel breakdown can be differentiated: detected while ongoing or natural death. While the former category comprises all cases in which the cartel was detected by the European Commission while still operating - e.g., through an application of specific detection tools such as a leniency program - the latter category 
contains cartels that ceased to exist due to natural reasons - such as market entry, disputes among cartel members, technological change etc. - before they were detected by the European Commission at a later point in time.

In absolute terms and over the entire observation period from 2001 to 2015, in 56 out of 113 cartel cases, the cartel died of natural causes and was later detected by the European Commission. In the remaining 57 cases, the detection of the cartel by the European Commission was causal for the breakdown of the cartel. In relative terms, Figure 11 below shows the respective yearly values for the two bases 'decision year' and 'year of cartel cessation'.
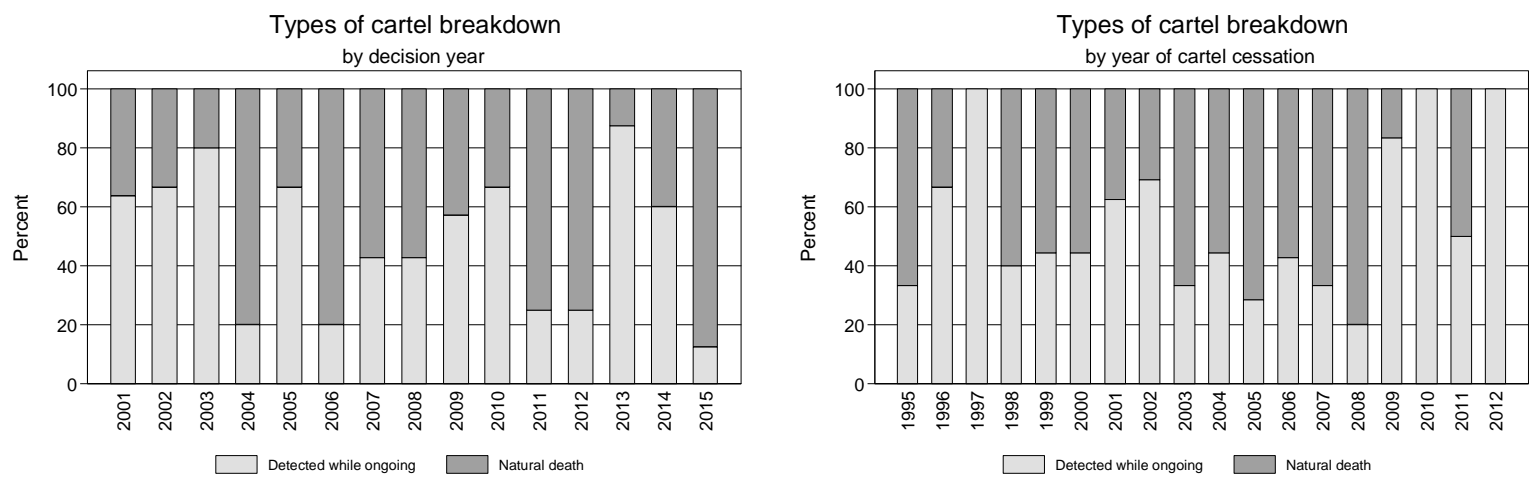

Figure 11: Types of cartel breakdown by year of decision and of cartel cessation Source: own figure based on ZEW cartel database

Focusing on the left-hand chart in Figure 11 first, it is generally revealed that the two types of cartel breakdown fluctuate quite substantially between the years leading to in sum roughly equal shares over the entire observation period. However, when the basis of analysis is changed from decision year to year of cartel cessation in the right-hand chart in Figure 11, partly substantial differences in the yearly pattern - however, only slight changes with respect to overall shares - are revealed. In particular, the apparent substantial increase in the 'detected while ongoing' category in the last few years can be taken as piece of evidence for an increasingly active detection of cartel cases by the Commission, e.g., through the application of leniency programs or international cooperation within the ECN or the ICN.

More generally, in thinking about the significance of both types of cartel breakdown, it could be argued that the 'detected while ongoing' cases are more valuable to society as they end a still ongoing (harmful) infringement of competition law. However, although this argument has some merit, there is no doubt that detecting and deciding on cartel cases that experienced an earlier natural death certainly remains an important enforcement activity as well - first and foremost for deterrence purposes. 


\subsection{Cartel duration}

The final characteristic of our quantitative assessment of EU cartel cases decided between 2001 and 2015 is the duration of cartels. In general, cartel duration is expected to be dependent on a multitude of different factors - including partly those cartel characteristics already discussed in earlier sections above. As a consequence, any descriptive quantitative analysis - being unable to control for the possible impacts of a multitude of different factors in parallel - must be exceptionally careful in the interpretation of the obtained averages and simple correlations.

The usual starting point for an assessment of cartel duration is the number of months the respective cartels existed before they either died of natural causes or were detected by the European Commission. In this respect, Figure 12 below plots the total cartel duration separately for all 113 cartel cases decided in our observation period (ordered by the date of detection).

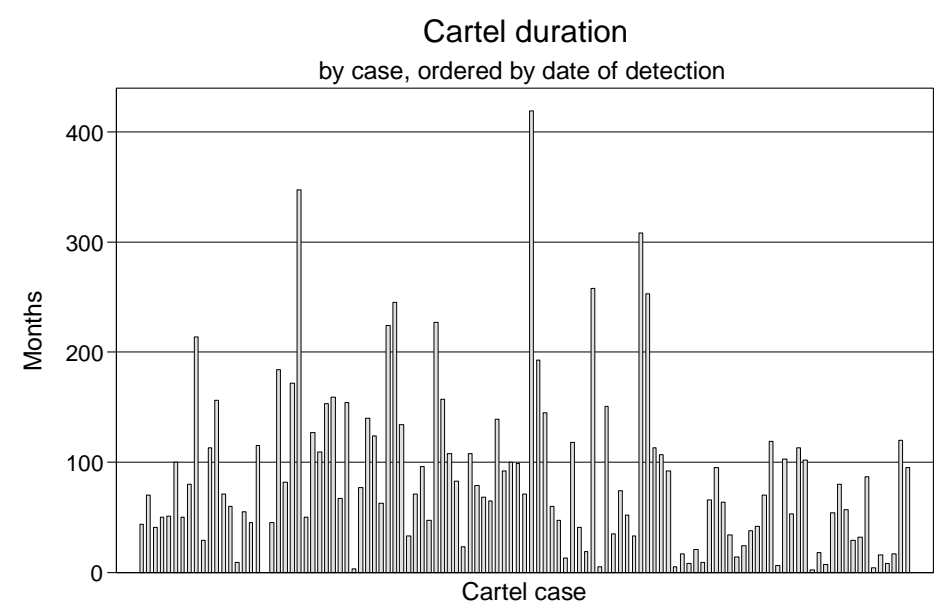

Figure 12: Total cartel duration of all 113 cartel cases (in months, by year of detection) Source: own figure based on ZEW cartel database

As shown in Figure 12, the total duration values fluctuate quite substantially with the shortest cartel - a subcartel of the Automotive wire harnesses case (Case COMP/39.748) -showing a total duration of only 2 months while the longest cartel - the Animal Feed Phosphates cartel (Case COMP/38.866) - lasted for 419 months, i.e. nearly 35 years. On average over the entire observation period, a cartel lasted for 87 months - allowing the important general conclusion that firms are regularly able to install and sustain workable cartel agreements. Furthermore, although the shorter duration of cartels that were detected more recently already becomes apparent from Figure 12, we will discuss this observation in greater detail in the subsequent analysis of average yearly duration values. Finally yet importantly, differentiating between the two types of cartel breakdown discussed in the previous section, we find that cartels dying of 
natural causes lasted shorter - showing an average duration of 77 months - compared to cartels that were detected by the Commission (showing a duration of 97 months on average).

Starting to think further about the most suitable basis for a meaningful analysis of cartel duration, our general discussion in Section 3.1 above identified three different possible bases: the year of decision, the year of detection and the year of cartel cessation - with particularly the letter two appearing as suitable bases for an assessment of cartel duration. Figure 13 below therefore shows the average yearly cartel duration by year of detection and year of cartel cessation.
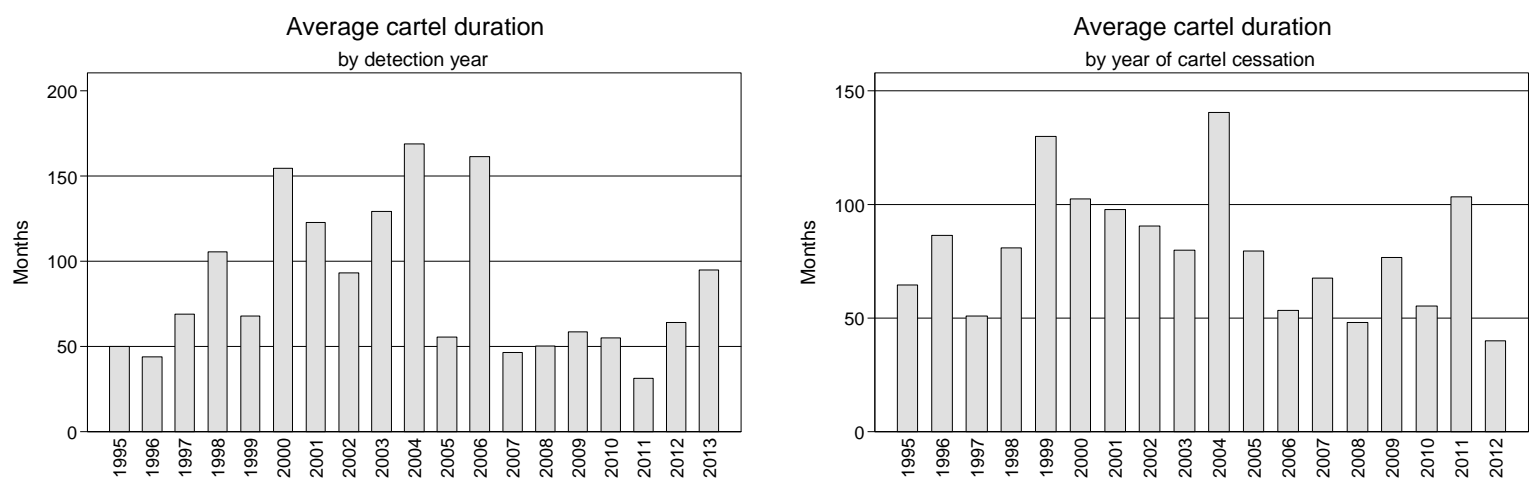

Figure 13: Average cartel duration by year of detection and year of cartel cessation Source: own figure based on ZEW cartel database

Starting our discussion with the results for the detection year, the left-hand chart in Figure 13 shows that average cartel length fluctuates quite substantially within the spectrum of 40 months in 2011 and 170 months in 2004. However, subdividing our observation period into the three equally-sized subperiods of five years each reveals that the average duration first increased from 72 months in the 2001-2005 period to 112 months in the 2006-2010 period; however, subsequently experienced a substantial reduction in the average duration to about 51 months in the most recent 2011-2015 period. In other words, the recently detected cartel cases were shorter and therefore most-likely also less harmful than the earlier cartels that partly reached average durations of more than 12 years. This development - which is found to be even more pronounced in the analysis based on the year of cartel cessation shown in the righthand chart in Figure 13 - can be seen as piece of evidence for a successful EU cartel policy in the last two decades.

Subsequent to the study of the developments of average cartel durations over time, the respective duration information on the cartel-level can be combined with further characteristics of cartels discussed above. However, due to the fact that a multivariate regression approach would be needed to disentangle the separate (potential) drivers of cartel duration, we would like to limit our further discussions to the relationships between cartel 
duration and the involved industry as well as the type of infringement (both shown in Figure 14 below).
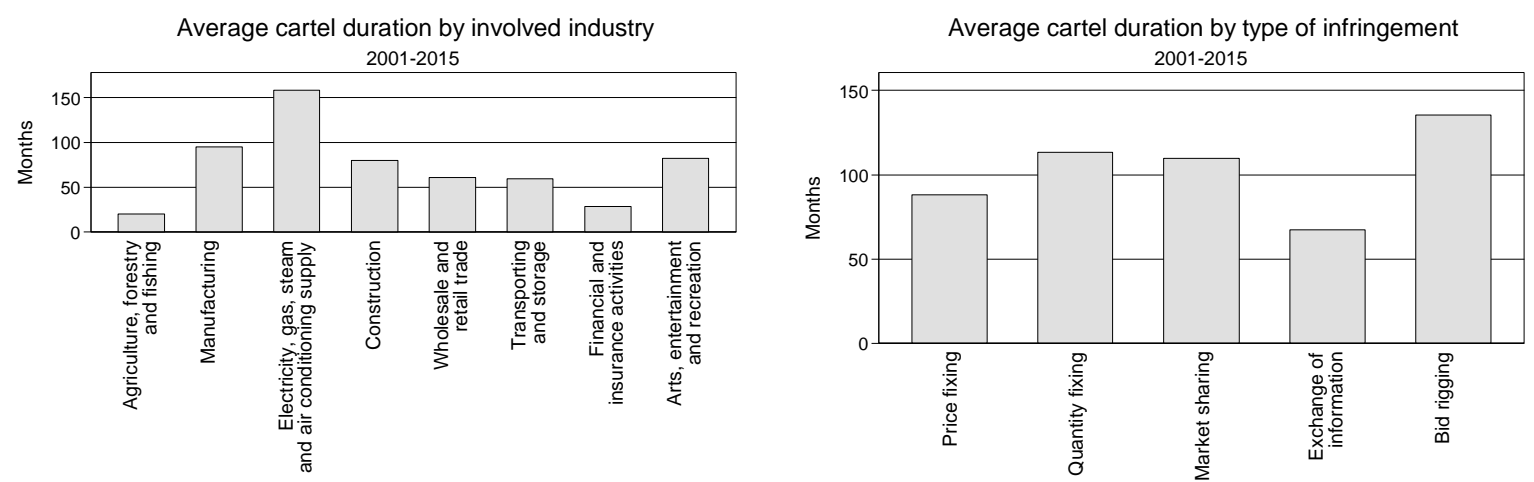

Figure 14: Cartel duration by involved industry and type of infringement Source: own figure based on ZEW cartel database

As revealed by the left-hand chart in Figure 14, cartels in the electricity, gas, steam and air conditioning supply industry are found to have lasted the longest with an average duration of about 158 months. However, as discussed in Section 3.3 above, only two cartels were decided in the entire observation period in this industry thus limiting the insights gained from this finding. Cartels in the manufacturing industry - comprising about 79 percent of all cartels in the observation period - are found second with an average duration of 95 months (and therefore clearly above the average of 87 months for cartel duration across all industries).

Turning to average cartel durations for the different types of infringement - shown in the right-hand chart in Figure 14 - bid rigging infringements are found to last longest with an average duration of 136 months, followed by quantity fixing (113 months), market sharing (110 months), price fixing (88 months) and exchange of information (67 months). However, it is important to remind that particularly bid rigging cartels are rather rare occurrences with in sum only 4 cases in our observation period. Furthermore, our discussions in Section 3.5 revealed that cartel agreements that included some form of illegal exchange of information increased its share substantially in recent years - a period that is also characterized by a reduced average duration of cartels. Both examples therefore suggest that any definite conclusions based on our descriptive quantitative analysis should be avoided.

Before we turn to a detailed characterization of the EU cartel enforcement process in the subsequent chapter, we close this section with the presentation and discussion of two scatter plots with cartel duration on the vertical axis and the following two variables - introduced and 
discussed in previous sections above - on the horizontal axis: number of firms and combined market share $^{20}$ (see Figure 15).
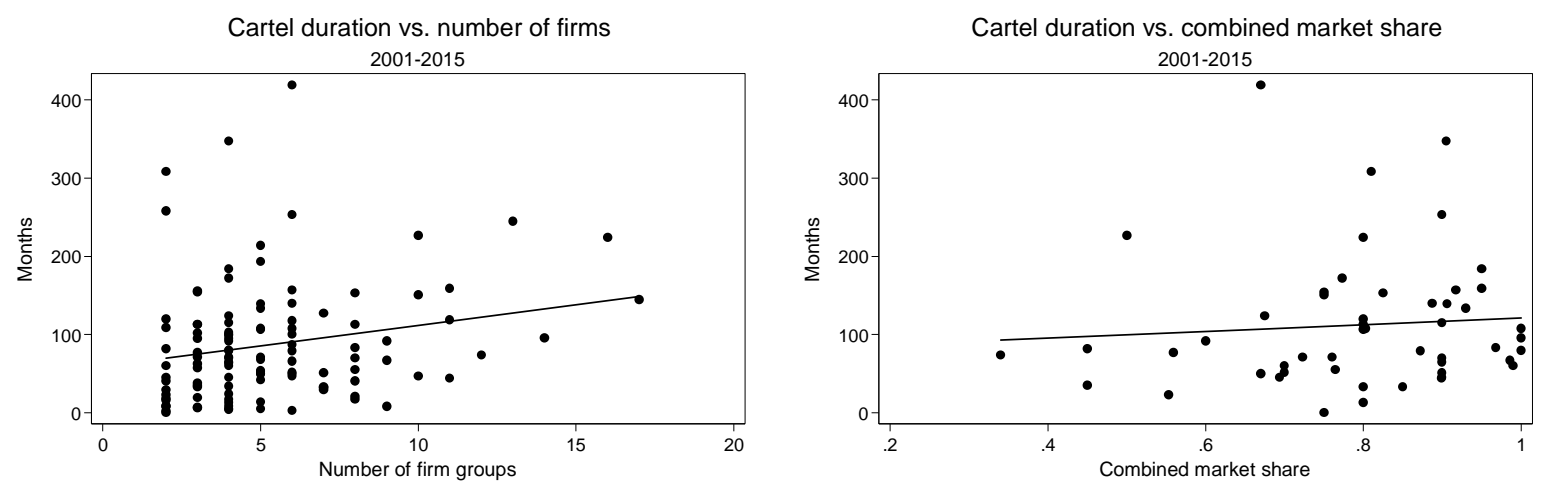

Figure 15: Cartel duration vs. number of firms and combined market share Source: own figure based on ZEW cartel database

Starting our discussion of Figure 15 with the left-hand chart, plotting firm groups against cartel duration first reveals a substantial variation in duration for cartels with an identical numbers of firm groups. For example, while the clear majority of cartels including two, four or six firm groups ended before reaching a duration of 100 months, all three categories also show cartels that managed to exist significantly longer. Considering all observations and including a simple regression curve reveals that on average cartel duration increases with the number of firm groups involved. Although surprising at first glance - having in mind the theoretical argument that cartels with an increasing number of firm groups are more difficult to implement and sustain - possible explanations are either a certain centralization of cartel organization activities by, e.g., an industry association or alternatively the fact that an increasing number of firm groups makes it more likely that the cartel includes all or nearly all firm groups operating in the industry (and therefore turns out to be more stable than cartels with a substantial number of outsiders).

In fact, whether the latter argument has some merit can be investigated further by using the right-hand chart in Figure 15. Plotting cartel duration against combined market shares indeed reveals that cartels with higher combined market shares last longer than cartels with lower combined market shares. However, as indicated by the small slope of the regression curve, the effect appears to be rather small.

20 As already mentioned in Section 3.2 above, missing information on combined market shares allows us to include only 51 cases. 


\section{Characterization of the EU Cartel Enforcement Process from 2001 to 2015}

In this section, we complement our assessment of EU cartel cases with a detailed quantitative analysis of the EU cartel enforcement process - subdivided further into (1) its duration, (2) types of cartel detection, (3) the leniency program, (4) the settlement procedure (5) fines imposed by the European Commission and (6) the appeals process with the General Court (GC) and (possibly) the European Court of Justice (ECJ).

\subsection{Duration of the enforcement process}

As already sketched in Section 2.1 above, the EU cartel enforcement process can broadly be subdivided further into two main stages: detection, investigation and decision by the European Commission and the (optional) investigation and decision of the General Court as first-stage appellate court and the European Court of Justice as the second-stage and highest appellate court in cartel cases in the European Union. In the following two subsections, we present initial general information on the duration of the respective processes in our observation period from 2001 to 2015.

\subsubsection{Duration of investigations by the EC}

The natural starting point for an assessment of the duration of the cartel enforcement process is the analysis of the total duration of the EC investigations on a case-by-case basis. Facing the need to identify the respective start and end dates, the latter is rather easy to define with the date of the EC decision. The choice of the start date of the investigation, however, is less trivial and offers several alternatives such as, e.g., the date of a dawn raid, the allocation of a case number, the opening of official proceedings etc. In the following, we consistently use the earliest event explicitly mentioned in the decision documents (e.g., the date of the first leniency application) as start date of the investigation. Figure 16 below plots the resulting durations for all 90 decided cases in our database (ordered by decision date). 
Time span between beginning of investigation and decision

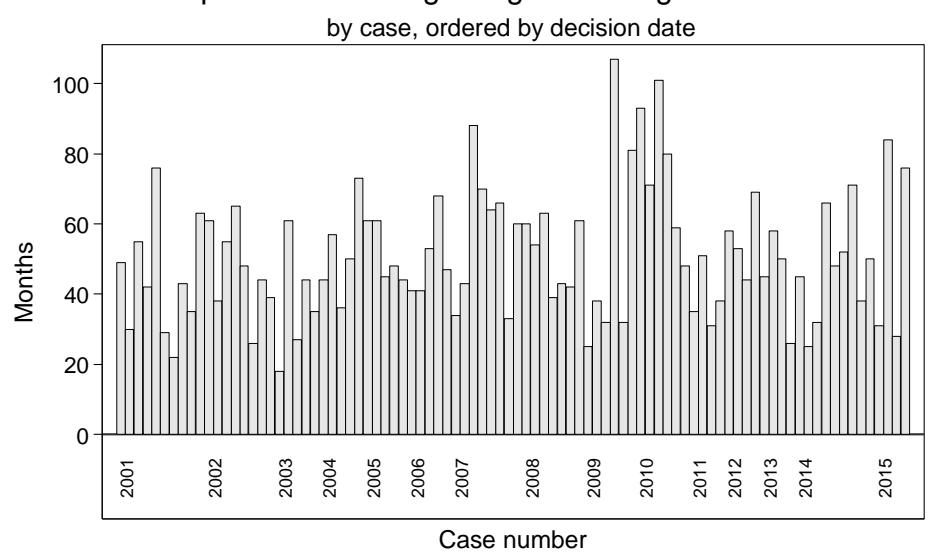

Figure 16: Time span between beginning of investigation and decision Source: own figure based on ZEW cartel database

As shown in Figure 16, the duration of EC investigations fluctuates quite substantially with the shortest case being below 20 months and the longest case overtopping the 100 months threshold. In the years 2009 and especially 2010, a substantial increase in the duration of case investigations is found - possibly related to the large number of firm groups that were involved in the respective cases (see Section 3.1 above for quantitative evidence) and the experimental stage of the settlement procedure (discussed further in Section 4.4 below). The specific situation in the year 2010 is also reflected in the average duration of EC investigations - again based on the decision year - shown in Figure 17 below.

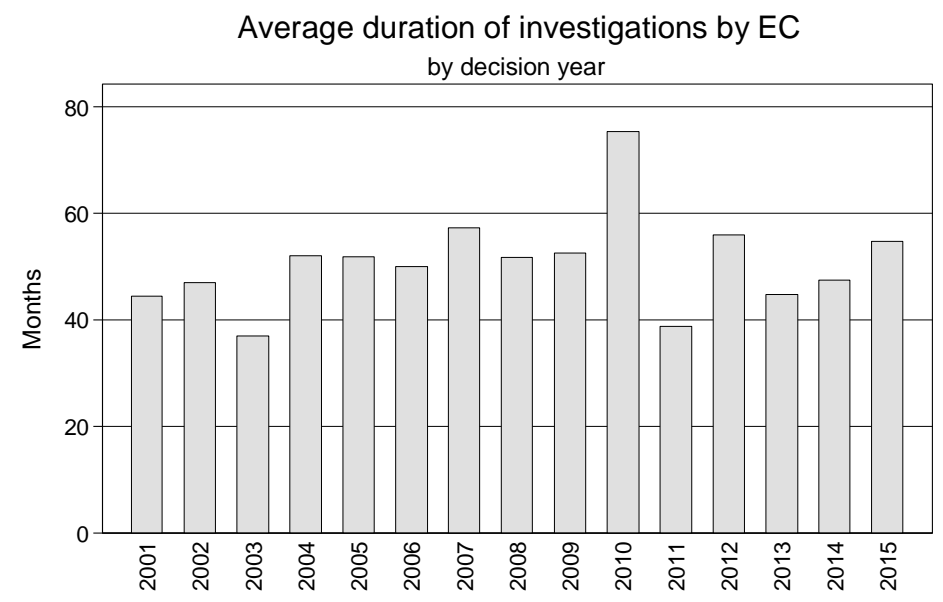

Figure 17: Average duration of investigations by EC

Source: own figure based on ZEW cartel database

As further revealed by Figure 17, the average duration of EC investigations followed an increasing trend from 2001 onwards until the largest average duration was reached in 2010. This is also reflected in the average values when again applying our three five-year periods: the average duration increased from 46 months in the 2001-2005 period to 57 months in the 
2006-2010 period. However, interestingly, the most recent and final period from 2011-2015 is then characterized by a clear decrease in the average duration of EU investigations to 48 months. Although a more detailed investigation of possible drivers behind this development will be provided in Section 4.4 below, the introduction of the settlement procedure in 2008 taking first effect in the year 2011 - might at least be part of the answer.

Before we turn to the duration of investigations by the two appellate court stages in EU cartel cases in the subsequent section, an analysis of the time span between the end of the cartel and the beginning of the investigation promises to provide additional insights - in light of the finding in Section 3.6 above that about half of all cartel cases were detected after the natural death of the conspiracy. Figure 18 below therefore plots the respective time span on a case-by-case basis (ordered by decision date).

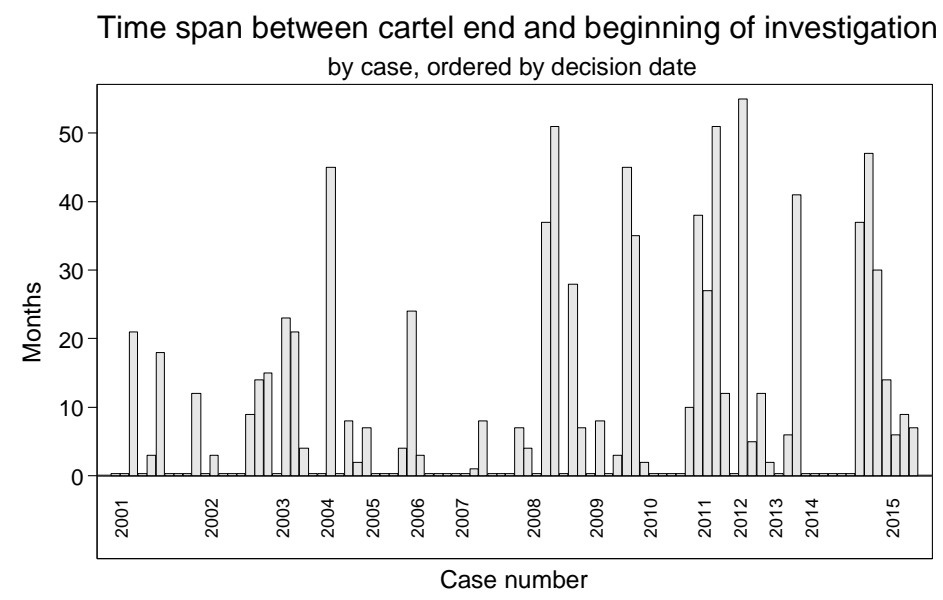

Figure 18: Time span between cartel end and beginning of investigation Source: own figure based on ZEW cartel database

As shown in Figure 18, the decided cases can be subdivided further into cases in which the investigation started immediately - i.e., cases in which the EC detected the infringement represented by the absence of any bar of visible size in Figure 18 and cases in which the EC received knowledge of the cartel after it was already terminated. Concentrating our further discussions on the latter group of cases, Figure 18 generally reveals that - over time - the share of older cartels that were eventually detected by the EC increased significantly. While the first subperiod from 2001-2005 shows an average duration of about 13 months, the time gap increased to 17 months in the $2006-2010$ period and to 23 months in the most recent 2011-2015 period. The introduction and reform of the leniency program - discussed in greater detail in Section 4.3 below - together with increased compliance efforts within firms also allowing the internal detection of past cartels - might have contributed to this development. 


\subsubsection{Duration of investigations by the General Court/European Court of Justice}

Subsequent to a cartel decision by the European Commission, the respective cartel members have the possibility to appeal the decision with the General Court (GC) as first-stage appellate court and the European Court of Justice (ECJ) as second-stage and highest appellate court for cartel cases in the European Union. While a detailed quantitative assessment of the appellate stages will be provided in Section 4.6 below, Figure 19 presents the respective average duration of both stages based on the decision date.

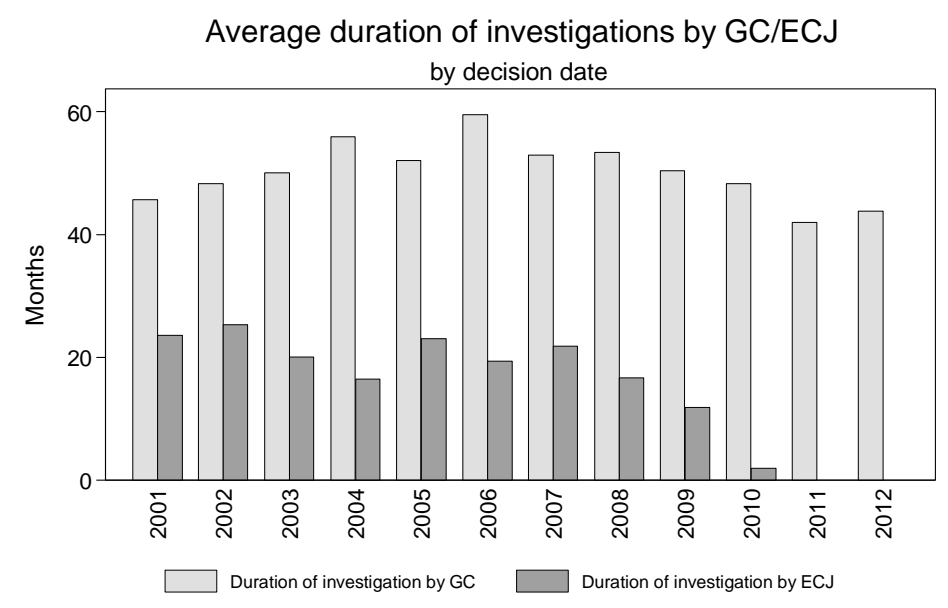

\section{Figure 19: Average duration of investigations by GC/ECJ}

Source: own figure based on ZEW cartel database

As shown in Figure 19, the average duration of GC investigations experienced a significant increase in the first half of the (shorter) observation period from 2001 to 2012; however, was subsequently followed by a comparable decrease in the second half. Expressed in numbers, while the first six year period from 2001-2006 shows an average duration of 52 months, the second six year period from 2007-2012 is characterized by a slightly lower average duration of 50 months. Arithmetically, these differences are largely driven by the clear reductions in the number of cases in the years 2011 and 2012 - which might change in the years to come if pending GC cases will be decided.

Turning from the average duration of investigations by the GC to the respective results for the ECJ, it is important to remind that both courts differ with respect to their activity spectrum. While the former reinvestigates the entire case - therefore leading to investigation durations comparable to the Commission's - the ECJ investigation is limited to a review whether existing laws and regulations were applied correctly. This substantially limited activity spectrum is also reflected in a substantial reduction in the average duration of an ECJ investigation (compared to the GC stage). In fact, as revealed by Figure 19, the average duration not only started at a level roughly half of that of GC investigations but even shows 
further reductions in subsequent years. However, the fact that several cases are still pending either at the GC or the ECJ is again likely to change the respective more recent values as more and more final GC/ECJ decisions will become available (see, e.g., Smuda et al. (2015) for an econometric analysis of the determinants of appellate court decisions in EU cartel cases).

\subsection{Type of cartel detection}

Subsequent to an initial characterization of the duration of the cartel enforcement process, the natural starting point of a closer investigation of the separate enforcement stages is a discussion of the type of cartel detection. Although our discussions on the type of cartel breakdown in Section 3.6 above already provided some insights in this respect - namely by differentiating between cartels that were ended by detection through the EC and cartels that ceased to exist due to natural causes - this perspective can be extended further through a categorization of all cases into (1) commission investigation (CI) ${ }^{21}$ that ends the cartel, (2) CI after the cartel ended, (3) leniency program (LP) application that ends the cartel, and (4) LP application after the cartel ended. In other words, by applying the described categorization, we are not only able to differentiate between the relative importance of the two most important detection instruments - CI and LP - but we are also in the position to link this knowledge with information whether the respective tools ended the infringements or were rather applied at a later point in time. Figure 20 below presents the respective shares of the four categories over time based on the year of detection.

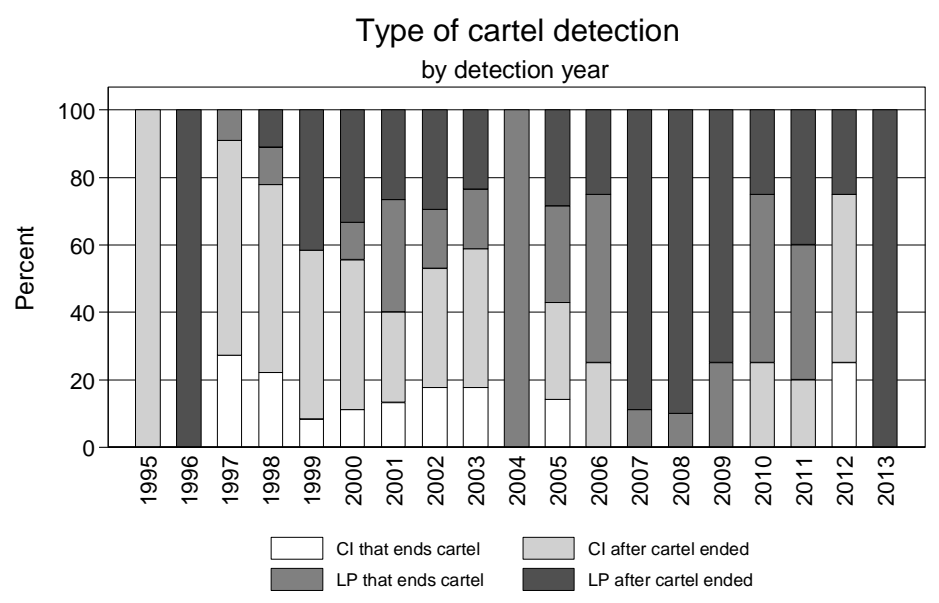

Figure 20: Types of cartel detection

Source: own figure based on ZEW cartel database

21 The 'commission investigation' (CI) variable consists of several different detection tools such as particularly complaints and information provided by other competition authorities (or other comparable sources). As such more detailed information is only available for a rather small number of cases, a further differentiation of the CI variable would have resulted in a substantial reduction of the size of the sample. 
As generally shown in Figure 20, the different types of cartel detection fluctuate quite substantially over time. While in four years of the entire observation period - 1995, 1996, 2004 and 2013 - only one detection type was applied, the majority of in sum 12 years shows a combination of either three or all four types.

Aiming at identifying certain trends in the detection of cartels, it becomes apparent that the first two thirds of the observation period were characterized by a relatively large share of CIrelated cartel detection - first and foremost after the end of the cartel agreement but also - on a regular basis - in cases where the CI caused the end of the cartel. However, since 2007, both forms lost in importance leading to a corresponding increase in LP-related cartel detection. This general observation is in line with various statements from officials from competition authorities reporting that LPs have turned out to be such an effective detection tool that CIrelated activities are simply not needed to a larger degree to fully use existing staff capacities.

Furthermore, as also shown in Figure 20, the shares of LPs as detection tool applied after the cartel ended gained in importance substantially in recent years. Although admittedly speculative, the existence of LPs is likely to have promoted the incentives of firms to come forward with sufficient proof of a former cartel in exchange for a fine reduction or even a fine waiver (before another former cartel member decides to do so). A more detailed characterization of the leniency program is provided in the following section.

\subsection{Leniency program}

A leniency program (LP) generally offers law infringers (i.e., individuals or companies) either a fine reduction of even full amnesty if they disclose an infringement to the responsible authority and (fully) cooperate with it in the subsequent investigation. The degree of fine reduction typically depends on the point in time at which the infringer submits evidence (i.e., before or after the authority has started an investigation) and what kind of evidence is brought forward (i.e., how helpful the evidence is in proving the infringement).

In the EU, the absence of fines for individuals involved in a cartel agreement directly implies a focus on corporate leniency programs only. The original version of such a program for cartel infringements was introduced in $1996^{22}$ followed by two revisions: a substantial one in $2002^{23}$ and a comparably minor one in $2006^{24}$. The conditions for a leniency-related fine

22 Commission Notice on the Non-Imposition or Reduction of Fines in Cartel Cases, Official Journal of the European Commission, C 207, 1996, 4-6.

23 Commission Notice on Immunity from Fines and Reduction of Fines in Cartel Cases, Official Journal of the European Commission, C 45, 2002, 3-5.

24 Commission Notice on Immunity from Fines and Reduction of Fines in Cartel Cases, Official Journal of the European Commission, C 298, 2006, 17-22. 
reduction or even amnesty were initially set out in the 'Commission Notice on the NonImposition or Reduction of Fines in Cartel Cases' of 1996. The notice defined three different categories of fine reductions: (1) Non-imposition of a fine or a very substantial reduction in its amount (at least 75\% up to total exemption), (2) substantial reduction in a fine (between 50\% and 75\%), and (3) significant reduction in a fine (between 10\% and 50\%).

Fine reductions in the categories (1) and (2) were granted to firms which met the following criteria: (a) it is the first to adduce decisive evidence of the cartel's existence; (b) it puts an end to its involvement in the illegal activity no later than the time at which it discloses the cartel; (c) it provides the Commission with all the relevant information and all the documents and evidence available to it regarding the cartel and maintains continuous and complete cooperation throughout the investigation; and (d) it has not compelled another enterprise to take part in the cartel and has not acted as an instigator or played a determining role in the illegal activity. In order to qualify for a category (1) fine reduction, the firm additionally must have informed the Commission about a secret cartel before the Commission has started to undertake an investigation. Firms who cooperated with the Commission without having met all the conditions set out under (a) to (d) above still had the possibility to benefit from a category (3) fine reduction.

Although the first EC leniency program already generated a significant number of cases of self-reporting, a lack of transparency was identified as key obstacle for an even greater adoption. In particular, even if a firm met all the requirements mentioned above, it still would have faced a substantial uncertainty whether it qualified for full immunity from fines. With the first revision of the Notice in 2002, the EC aimed at improving the identified transparency problems by particularly guaranteeing full immunity from fines with certainty for the first firm that submits sufficient evidence enabling the Commission to adopt a decision to carry out an investigation. Applications that do not meet these high standards can still qualify for a reduction of 30 percent to 50 percent for the first runner-up, 20 percent to 30 percent for the second and up to 20 percent for all other firms if the reported evidence provides 'significant added value'.

In its second (minor) revision of the program in 2006, the EC, on the one hand, specified several procedures, most notably the rules for submission by introducing an explicit list of the evidence's content in the form of a corporate statement. On the other hand, a marker system was introduced that basically aims at securing the correct place of the reporting firm in the order of all reporting cartel members. 
Turning from the brief general set-up (and further development) of the leniency program in the European Union to a quantitative analysis of the 90 decided cases in our observation period, in sum 33 decisions were taken by the Commission on the basis of the 1996 leniency notice, compared to 32 decisions under the 2002 notice and 25 decisions under the 2006 notice. Although this aggregated information already allows the conclusion that the leniency program was regularly applied, more information on particularly the development of the application numbers of the program over time as well as the average reduction reached is necessary to further assess the impact and success of the program (and its revisions). Figure 21 below therefore provides the respective information for the entire observation period from 2001 to 2015.

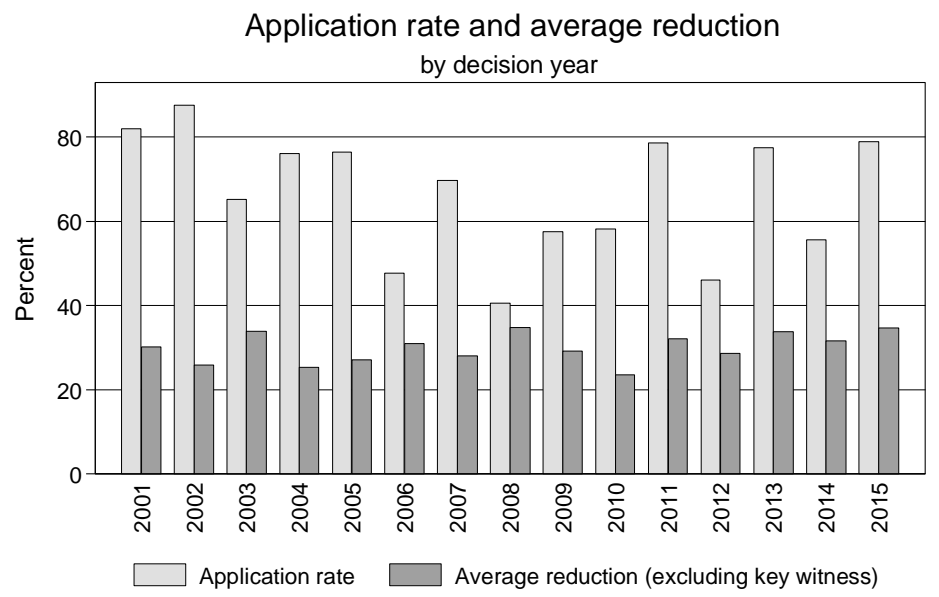

Figure 21: Application rate and average reduction Source: own figure based on ZEW cartel database

Starting the discussion of Figure 21 with the application rates, it is revealed that they diverge quite substantially during the observation period. While the first subperiod from 2001-2005 shows a rather high average application rate of 79 percent, the subsequent period from 20062010 was characterized by a significant drop to 56 percent. However, the most recent fiveyear period from 2011-2015 again shows an increase in the application rate to 63 percent. Although admittedly speculative, one reason for the temporary decrease in the application rate could be seen in the uncertainties created by the substantial revision of the leniency notice in 2002 described above. Once the Commission clarified these issues through a consistent application of the new rules, the respective firm groups again more and more decided to apply for leniency (see generally Hoang et al. (2014) for an econometric approach to the question of determinants of self-reporting as part of the EC leniency program). 
Turning from the application rate to the average reduction due to leniency, Figure 21 also shows the respective values excluding the respective key witness. ${ }^{25}$ The average reduction over the entire observation period is found to lie at 29 percent, with only limited variation as reflected in the three averages for the subperiods: 28 percent for both the 2001-2005 period and the 2006-2010 period and 32 percent for the most recent 2011-2015 period. However, especially the recent measurable increase together with the (again) high application rates suggest that the leniency policy is an important and functioning tool of contemporary EU cartel policy.

Before we turn to a discussion of a further and more recently introduced tool promising further fine reductions - the settlement procedure - our assumption in Section 4.2 above that the leniency program is creating a certain tension in cartel agreements - possibly leading to a race to the enforcer's door - deserves a further investigation. For this purpose, Figure 22 not only shows the number of leniency applicants but also the temporal order of the incoming applications.

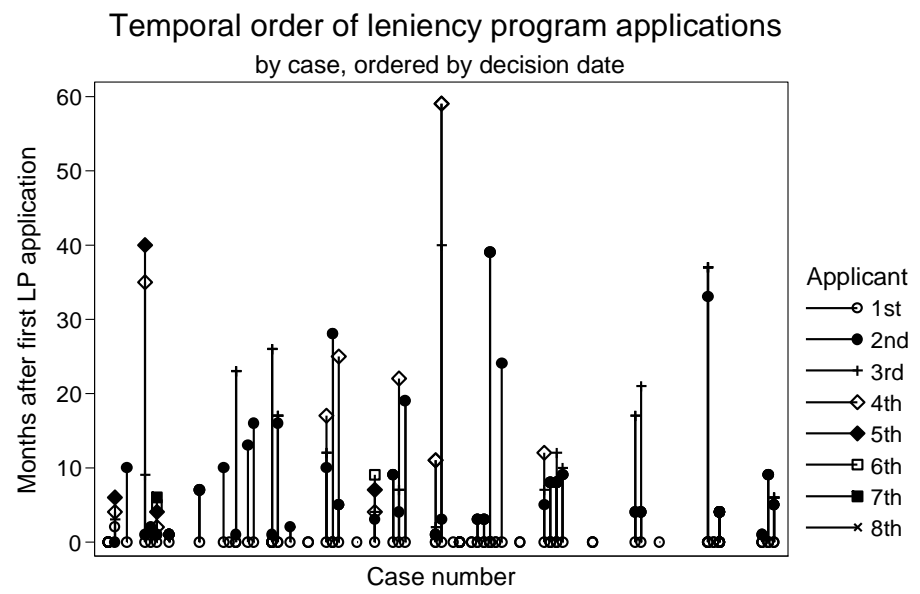

Figure 22: Temporal order of leniency program applications Source: own figure based on ZEW cartel database

Due to data limitations, Figure 22 only displays the temporal order for in sum 50 decided cases ordered by decision date. In 11 out of these 50 cases, only one firm group decided to apply for leniency, leaving 39 cases for an assessment of the temporal order of the at least two applications. As suggested by the figure, a 'race to the enforcer's door', i.e., two or more applications handed in in a very short time frame seems to be the exception rather than the rule with in sum only 9 cases showing the respective characteristics. In the majority of cases, a substantial amount of time passes by before further applicants decided to come forward and

25 As the key witness typically receives a fine waiver, its inclusion would complicate an interpretation of the results shown in Figure 21. 
apply for leniency. In other words, the majority of further leniency applications is received while the European Commission is already investigating the case - suggesting that firms decide to apply at the point in time at which it becomes sufficiently likely that the Commission has sufficient evidence to fine the respective cartel members (but a leniency application is still likely to result in a fine reduction of 10 to 20 percent).

\subsection{Settlement procedure}

The EU Settlement Procedure was introduced in late June 2008 with Regulation 622/2008 ${ }^{26}$ and a Commission Notice ${ }^{27}$ on the conduct of settlement procedures. It enables the European Commission to close investigations faster by eliminating or reducing several procedural steps - such as full access to file, drafting and translations or oral hearings and interpretation required under the standard procedure. Parties who admit liability and waive these procedural rights receive a discount of 10 percent on the final fine imposed. Through the introduction of the settlement notice, the EU aims at enabling “... the Commission to handle faster and more efficiently cartel cases ...”28 thus freeing up resources for additional cases and strengthening the deterrence effect of cartel enforcement.

Aiming at providing descriptive quantitative evidence on the significance and impact of the settlement procedure - particularly on the duration of EC cartel investigations - Figure 23 plots the development of the number of cases decided by the European Commission from 2001 to 2015. As revealed by Figure 23, between 2010 and 2015, we observe in sum 18 settled cases out of which 5 cases $^{29}$ were hybrid settlements in which typically one of the companies decided to opt out of the settlement procedure. Furthermore, the first two cases settled in $2010^{30}$ - were special in the sense that they were converted into settlement cases relatively late in the investigation process thus questioning them as 'typical' settlement cases.

26 Commission Regulation (EC) No 622/2008 of 30 June 2008 amending Regulation (EC) No 773/2004, as regards the conduct of settlement procedures in cartel cases, OJ L 171/3, 1.7.2008. Commission Regulation (EC) No 773/2004 of 7 April 2004 relating to the conduct of proceedings by the Commission pursuant to Articles 81 and 82 of the EC Treaty (OJ L 123/18, 27.4.2004) lays down rules concerning the participation of the parties concerned in such proceedings.

27 Commission Notice on the conduct of settlement procedures in view of the adoption of decisions pursuant to Article 7 and Article 23 of Council Regulation (EC) No 1/2003 in cartel cases (2008/C 167/01), OJ C 167/1, 2.7.2008.

28 Commission Regulation (EC) No 622/2008, OJ L 171/3, p. 1.

29 The cases are Animal Feed Phosphates (Case COMP/38.866), Yen Interest Rate Derivatives (Case COMP/39.861), Euro Interest Rate Derivatives (Case COMP/39.914), Steel Abrasives (Case COMP/39.792) and Mushrooms (Case COMP/39.965).

30 The cases are DRAMs (Case COMP/38.511) and Animal Feed Phosphates (Case COMP/38.866). 


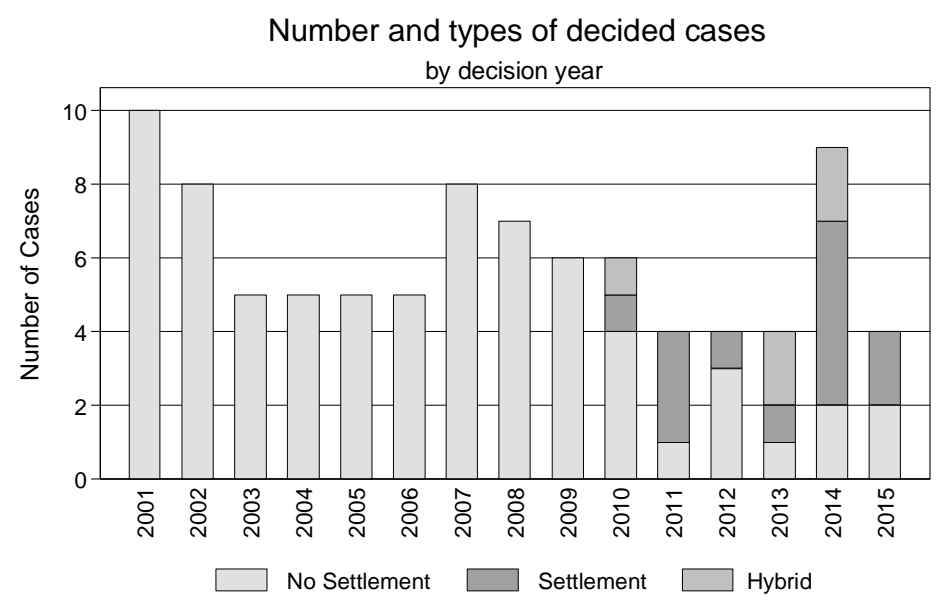

Figure 23: Number and types of decided cases

Source: own figure based on ZEW cartel database

Although Figure 23 certainly provides valuable insights on the increasing significance of the settlement procedure in recent cartel cases, the clearly communicated aim of the introduction of this additional policy tool was to shorten the duration of EC investigations. Aiming at investigating this issue further, Figure 24 plots the length of the EC investigation for all cases decided between 2001 and 2015.

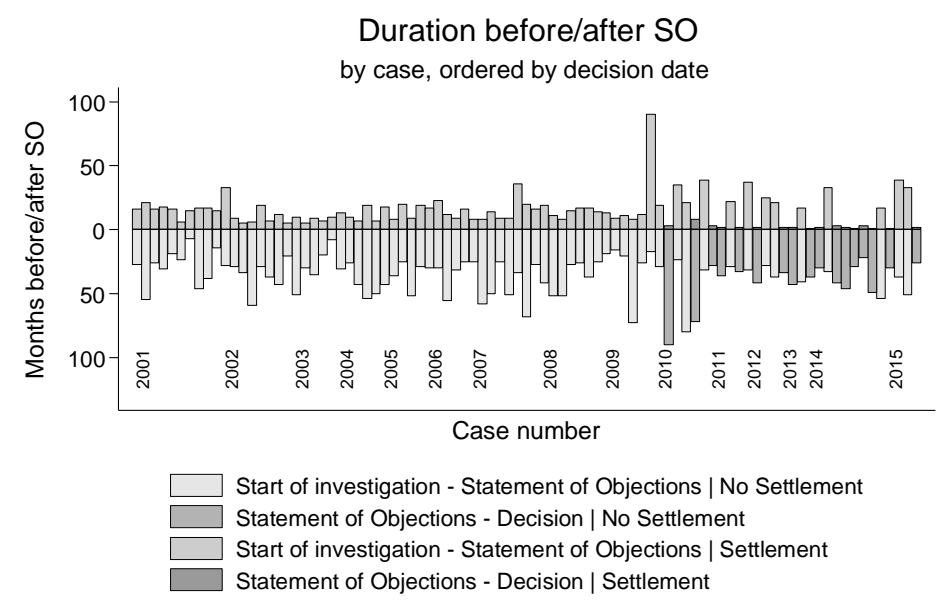

Figure 24: Duration before/after the statement of objection (SO) Source: own figure based on ZEW cartel database

As the settlement procedure is expected to shorten especially the time need from the so-called statement of objections ${ }^{31}$ (SO) to the decision, we subdivide the entire investigation period (on the vertical axis) into start of investigation up to the SO and from the SO to the final decision by the European Commission. The horizontal axis orders the case numbers according to their decision dates, i.e., the last case decided by the EC in 2015 is located at the very right

31 The statement of objections (SO) is a written document in which the Commission informs the parties concerned of the objections raised against them. 
of the figure. Furthermore, aiming at identifying possible differences between settled and nonsettled cases, Figure 24 further introduces separate colors for both stages of the settled cases (as also defined in the legend to the figure).

Abstracting from the few outliers with unusually long first or second stages, the probably most apparent finding of Figure 24 is the substantial reduction in the duration of the second stage for settled cases. As it is further revealed that the first stage of the respective settled cases does not show a substantial duration increase compared to their non-settled counterparts in the pre-settlement era - i.e., the respective post-SO activities are not simply shifted to the pre-SO stage ${ }^{32}$ - it can be said that our quantitative evidence supports the conclusion that the introduction of the settlement notice reached its main aim of reducing the overall duration of the EC cartel enforcement process (see Hüschelrath and Laitenberger (2015) for an econometric approach confirming this key result).

Another interesting observation has to do with the duration of non-settled cases since the EU Settlement Procedure was implemented. Here we see a clear increase in the duration of particularly the second stage (compared to the pre-settlement era) suggesting that the EC might prioritize settled cases over non-settled cases in their everyday work leading to a substantial increase in the duration of non-settled cases.

\subsection{Fines imposed by the European Commission}

The fine levels imposed by the European Commission on the respective cartel members are the key output of the entire cartel investigation and decision process. By imposing fines, the European Commission basically pursues two interrelated goals: punishing detected breaches of competition law and deterring future infringements. Aiming at implementing both goals in a transparent and effective fashion, the EC introduced first 'Guidelines on the method of setting fines' in $1998^{33}$ which were revised substantially in $2006^{34}$. In our observation period from 2001 to 2015, the 1998 fine guidelines were applied in 44 decisions, compared to 46 decisions in which the new 2006 fine guidelines were used. In the remainder of this section, we concentrate on the EC fine setting process as specified in the 2006 fine guidelines which can broadly be subdivided further into (1) the derivation of the basic amount of the fine, (2) fine adjustments due to the presence of aggravating or mitigating factors, and (3) the fixing of the overall fine imposed.

\footnotetext{
32 While the settled cases show an average length of 41 months from the beginning to the SO, the non-settled cases have an average of 35 months.

33 Guidelines on the Method of Setting Fines, Official Journal of the European Commission, C 9, 1998, 3-5.

34 Guidelines on the Method of Setting Fines, Official Journal of the European Commission, C 210, 2006, 2-5.
} 
Derivation of the basic amount of the fine

According to the 2006 fine guidelines, the derivation of the basic amount of the fine essentially depends on (1) the firm's turnover, (2) the gravity and (3) the duration of the infringement. In an initial step, the EC determines the firm's turnover of the relevant product in the affected market generated in the last full business year preceding the end of the infringement. The basic amount of the fine can reach up to 30 percent of these relevant sales depending further on, first, the gravity of the infringement (measured by factors such as the type of infringement, the combined market share and the geographic scope of the infringement). Second, the basic amount of the fine is directly influenced by the duration of the infringement. After fixing the appropriate percentage of the firm's cartel sales, the EC adds a duration multiplier, equal to the number of years in which the cartel was active. Furthermore, a so-called 'entry-fee' of 15 percent to 25 percent might be levied on top particularly for shorter cartels.

Fine adjustments due to the presence of aggravating and mitigating circumstances

Subsequently, the EC might adjust the basic amount of the fine by taking account of so-called aggravating and mitigating circumstances. Factors that can lead to an increase in the fine include ringleader status or recidivism - e.g., for repeat offenders the fine can be increased by up to 100 percent for each prior infringement - while passive membership in the cartel or cooperation efforts (outside the leniency program) might reduce the basic amount of the fine. From a quantitative perspective, Figure 25 below shows the yearly percentages of firm groups who faced aggravating and/or mitigating factors over the entire observation period from 2001 to 2015.

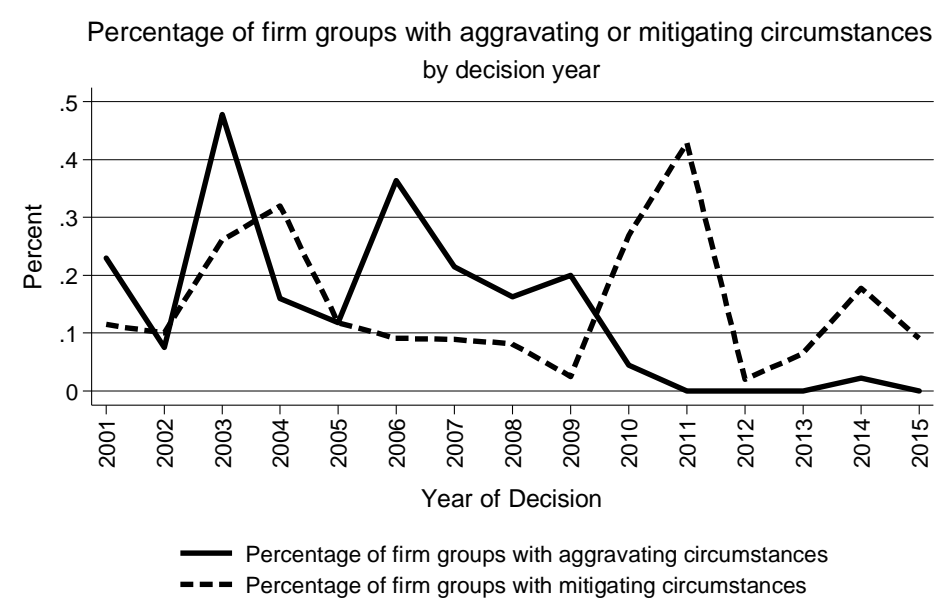

Figure 25: Percentage of firm groups with aggravating and mitigating circumstances Source: own figure based on ZEW cartel database 
Starting a detailed discussion of Figure 25 with the role of aggravating factors, it is shown that they played a significant role in roughly the first two-thirds of the observation period reaching percentage shares of close to 50 percent in 2003. However, since 2011, these factors substantially lost in relevance reflected in only one case in 2014 in which aggravating factors played a (small) role. In comparison, although also mitigating factors lost in importance substantially - particularly between 2005 and 2009 - the more recent years show a remarkable variation in the respective values overtopping the 40 percent threshold in 2011 and facing a drop to almost 0 percent in the year after. However, in contrast to the aggravating factors, mitigating factors were applied more consistently showing cases in every single year of the observation period.

Aiming at investigating the reduced role of both aggravating and mitigating factors a bit further, Figure 26 differentiates between different reasons within both factors. As shown in the left-hand chart in Figure 26, recidivism is found to be the dominant aggravating factor by far. Furthermore, while the role of cartel leader was also regularly used as aggravating factor in earlier cases, the criterion played no role in more recent EC case decisions. All other reasons are found to be of minor importance.
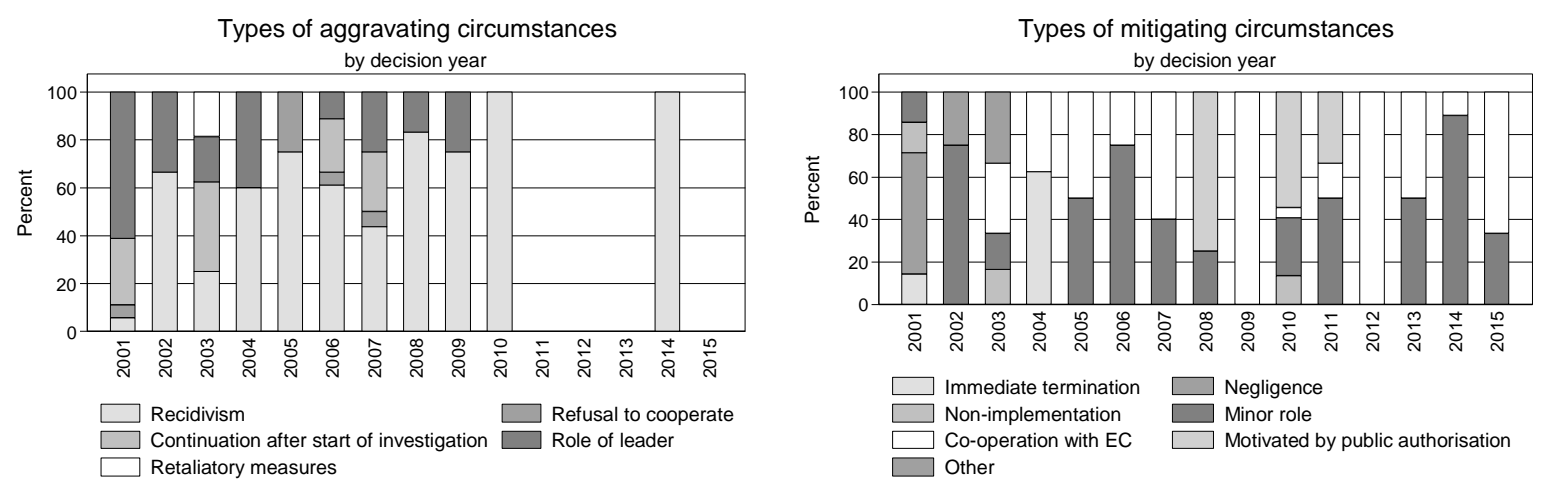

Figure 26: Types of aggravating and mitigating circumstances Source: own figure based on ZEW cartel database

Turning to the role of mitigating factors - plotted in the right-hand chart in Figure 26 - it is shown that both a minor role in the cartel and cooperation with the $\mathrm{EC}^{35}$ were the two dominant reasons for receiving a reduction of the basic amount of the fine. However, also the motivation by a public authority to initiate (or participate in) a cartel had a certain relevance in several years of the observation period.

35 Please note that this mitigating factor can be applied independent of the question whether the respective firm group has participated in the leniency program or not. 


\section{Fixing of the overall fine imposed}

After the derivation of the basic fine and the identification of possible aggravating or mitigating factors, the fixing of the overall fine eventually imposed on the cartel firm groups is conducted. According to the 2006 fine guidelines, the overall fine imposed must not exceed 10 percent of the firm's annual total turnover. If the firm belongs to a group where the parent company exercised decisive influence over the operations of the subsidiary, the benchmark is the group's annual turnover instead of the individual firm's annual turnover. Furthermore, if the investigation started more than five years after the end of the infringement, no fine can be imposed. Finally yet importantly, a fine can be reduced in exceptional cases in which the firm proves its 'inability to pay' and the imposition of the full fine would seriously jeopardize the survival of the firm.

As starting point for our quantitative assessment of the overall fines imposed, Figure 27 presents the absolute fines and the fines per firm group for the entire observation period from 2001 to 2015. In interpreting Figure 27, it is important to have in mind that the plotted fines refer to the respective decisions of the Commission, i.e., they take increases or reductions due to the presence of aggravating or mitigating factors as well as reductions due to application of the leniency program, the settlement procedure, and/or the just mentioned further reasons into account; however, they ignore possible further reductions as part of a possible appeals process.

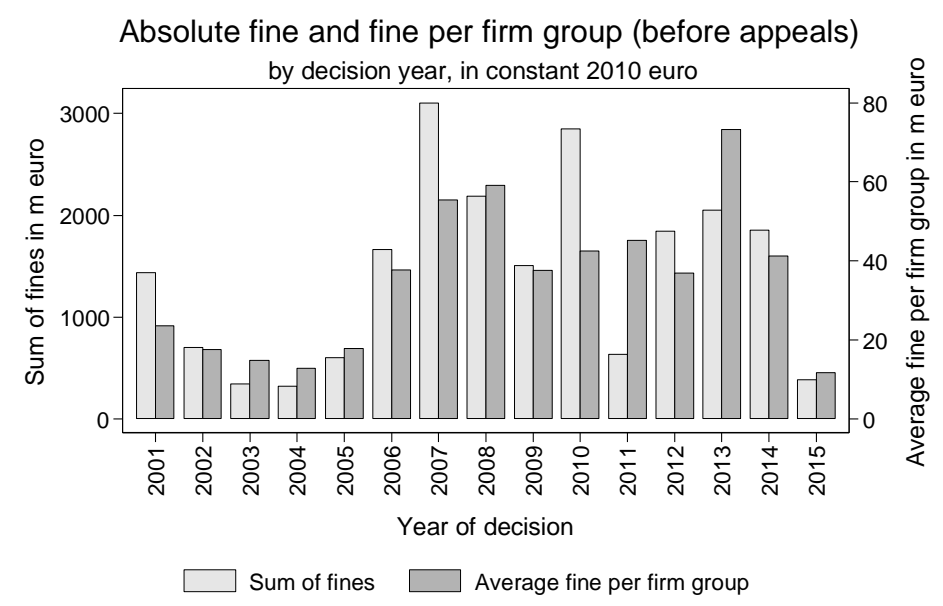

Figure 27: Absolute fine and fine per firm group (before appeals) Source: own figure based on ZEW cartel database

As shown in Figure 27, both the sum of fines as well as the average fine per firm group experienced a substantial increase in the years following 2005. While the sum of fines values still shows large variation - at least partly being explained by the differences in the number (and size) of decided cases in a given year - the average fine per firm group values show a 
substantially smaller variation suggesting that firms convicted for cartelization in recent years on average have to pay larger fines than they would have paid for the same infringement in more distant years. ${ }^{36}$ Expressed in numbers, while the first five-year period from 2001 to 2005 experienced an average fine per firm group of about $€ 17$ million $^{37}$, the respective average value increased substantially to about $€ 47$ million in the $2006-2010$ period. The most recent 2011 to 2015 period experienced both the highest and the lowest fine per firm group - in 2013 and 2015, respectively - resulting in an average value of €42 million.

Before we turn to a detailed discussion of the appeals process as the final stage of the entire EU cartel enforcement process, the derivation of basic amounts of fines and the subsequent various possibilities to face either increases or decreases of the basic fine suggest a final comparison of both values on a yearly basis for the entire observation period. Figure 28 therefore plots the final fine (per firm) without any increases or decreases as well as the final fine (also per firm) as eventually imposed by the Commission. Furthermore, based on this information, the average percentage reduction is calculated and included into Figure 28 as dotted line.

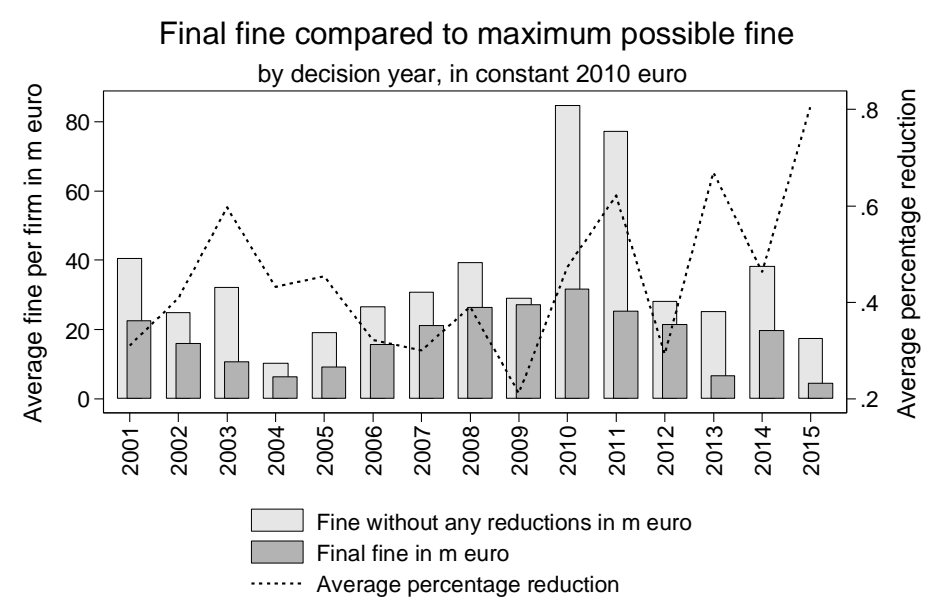

Figure 28: Final fine compared to maximum possible fine per firm Source: own figure based on ZEW cartel database

As shown in Figure 28, in the large majority of years in the observation period, the final fine stayed substantially below the maximum possible fine. In fact, the average reduction over the entire observation period lies at 45 percent, with the first five-year period from 2001-2005 showing an average of 44 percent, compared to 34 percent in the 2006-2010 period and 57

\footnotetext{
36 Although four cartel cases were decided by the European Commission in 2015, the respective fines imposed were low resulting in the substantial reduction in both 'sum of fines' and 'average fine per firm group' shown in Figure 27.

37 We deflated nominal fines using the Consumer Price Index for Europe taken from the OECD Main Economic Indicators (MEI) database.
} 
percent in the final 2011-2015 period. Although the maximum possible fine reported here has no direct link to an economically optimal fine, the observation of substantial average reductions of basic fine levels raises the question whether current fines are still large enough to reach the optimal level of deterrence.

\subsection{Appeals}

The appeals process - or alternatively the judicial review process as often referred to in the EU - offers the losing party of an administrative (or court) decision the possibility to seek reconsideration of their arguments - possibly leading to a diverging decision by an appellate court. Without denying its important constitutional role or even status as a human right, it is reasonable to assume that the implementation of an appeals process is motivated by two main goals. First, the implementation of an appeals process aims at reducing the occurrence of legal errors (e.g., as parties are more likely to file an appeal if the first decision was erroneous or by providing incentives to lower court judges to avoid erroneous decisions). Second, appeals help to refine existing laws and regulations (e.g., by reassessments of experienced appellate courts but also by providing signals to lawmakers on the efficiency of existing laws and regulations).

Under EU competition law in general and for EC cartel cases in particular, the appellate court proceedings can be either one- or two-stage. At the first stage, a cartel member that believes to have serious concerns with a (fining) decision of the EC can file an appeal with the General Court (GC) of the European Union. ${ }^{38}$ The GC - previously known as the Court of First Instance (CFI) - is composed of at least one judge from each member state. According to Article 254 TFEU, judges are appointed 'by common accord of the governments of the member states' for a renewable term of six years. The GC sits in chambers of usually three or five judges. Substantively, four main categories of argument can broadly be distinguished in an appeal against an EC cartel decision: fine levels, procedural aspects, facts/standard of proof aspects, and substantive assessment issues. In any case, the first-stage appeal must be initiated within two months of the earlier; either the publication of the Commission's decision or the notification of the firm group (Art. 263 TFEU).

Generally, the GC not only has the power to annul, reduce or increase the fines imposed by the EC; it also has full jurisdiction to review the entire Commission decision (including a repetition of the full assessment process). In practice, however, the GC usually focuses on an assessment of the factors linked to the correct application of the respective law provisions

38 See the consolidated version of the Rules of Procedure of the Court of Justice, Official Journal of the European Union, C 177/01, 2010, 1-36. 
such as cartel duration, the gravity of the infringement or the application of the leniency program. Typically, the GC does not aim at replacing the Commission's assessment of evidence with its own.

At the second stage of the appeals process in EC cartel cases, judgments of the GC can be appealed before the European Court of Justice (ECJ) by the unsuccessful party, i.e., either the convicted firm, the EC itself or both. The ECJ is the highest European appellate court and also has the power to annul, reduce or increase the fines imposed by the GC. However, in its proceedings, it limits itself to questions of law and has no jurisdiction to (re-)review the facts and analyze the evidence that the GC used to support its findings and decision.

Turning from a brief description of the appeals process in cartel cases to an initial quantitative assessment for our entire observation period from 2001 to 2015, out of a total of 600 firm groups convicted by the Commission to pay a fine for cartelization, 296 firm groups decided to appeal the decision of the EC at the GC and 120 firm groups ended up in the second-stage (either by their own decision or due to an appeal by the EC). Figure 29 below provides a more detailed characterization by plotting the yearly numbers and rates of appeals against EC cartel decisions for our observation period from 2001 to 2015 (focusing on the respective GC decisions only).

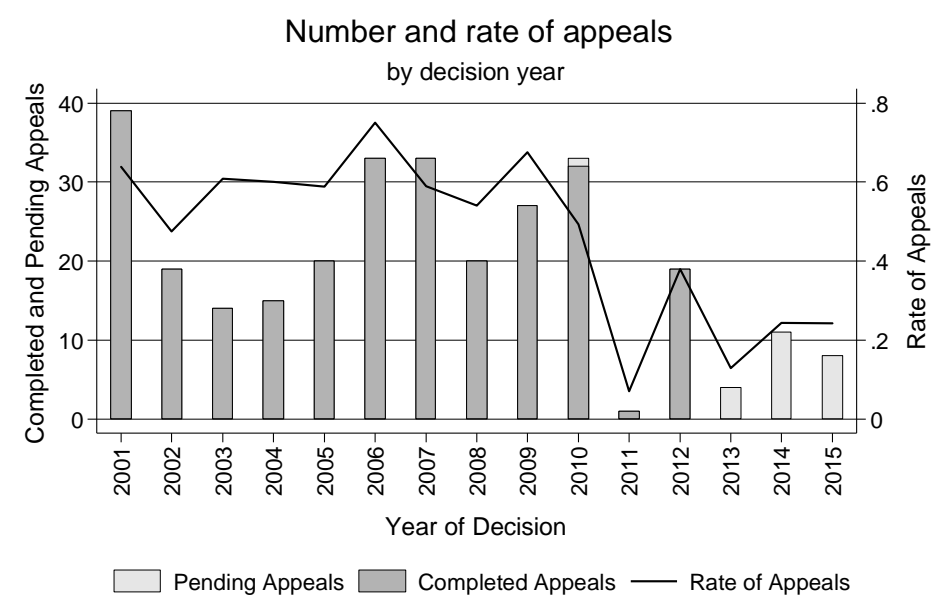

Figure 29: Number and rate of appeals (GC decisions only)

Source: own figure based on ZEW cartel database

As revealed by Figure 29, in the first ten years of the observation period, the number of appeals vary substantially with 39 appeals (2001) and 14 appeals (2003) delineating the spectrum. However, starting in 2011, the number of appeals experienced a substantial drop. While the average number of appeals in the 2001-2010 period is 25, the corresponding average for the 2011-2015 period is found to be substantially lower at only 9 appeals (a reduction of about 64 percent). 
In order to take account of the fact that different years show different numbers of decisions (with varying numbers of involved firms) and therefore different general possibilities to file an appeal, Figure 29 additionally plots the respective shares of firm groups that filed an appeal in the year of the respective EC decision. It is shown that the identified downward trend is confirmed by this alternative measure: while the 2001 to 2010 period saw an average appeal rate of 60 percent, the 2011 to 2015 period witnessed a substantial drop to 21 percent. Although various factors might have influenced this development - suggesting an econometric analysis as provided in Hellwig et al. (2016) - our descriptive findings here support the claim that the settlement procedure had a measurable impact on the number of appeals cases brought against EC cartel decisions. As one of the various requirements for a successful settlement with the EC is the admittance of liability for an illegal agreement of a certain scope and value of affected sales, the probability of a successful appeal is reduced substantially for settled cases - thus limiting appeals cases mostly to the (smaller and further shrinking population of) firm groups that decided not to settle with the Commission.

Finally yet importantly, as any appeal against a cartel decision by the Commission aims at reaching a fine reduction or even a fine annulment, the final step in our quantitative analysis must investigate the questions, first, to what degree the appeals were generally successful and, second, how successful they turned out to be for the appealing firm groups. In absolute terms and referring to the entire observation period from 2001 to 2015, the general appeal success rates diverge substantially between the two stages. While in sum 119 of the 273 first-stage appeals were successful (about 44 percent), the respective numbers drop substantially for second-stage appeals with only 12 successful out of 84 second-stage appeals leading to a success rate of about 14 percent (see, e.g., Hüschelrath and Smuda (2016) for an econometric analysis).

Turning to the question of how successful appeals have been, Figure 30 below shows the average percentage reduction due to appeal in combination with the respective average fines per firm group before and after the appeals process. 


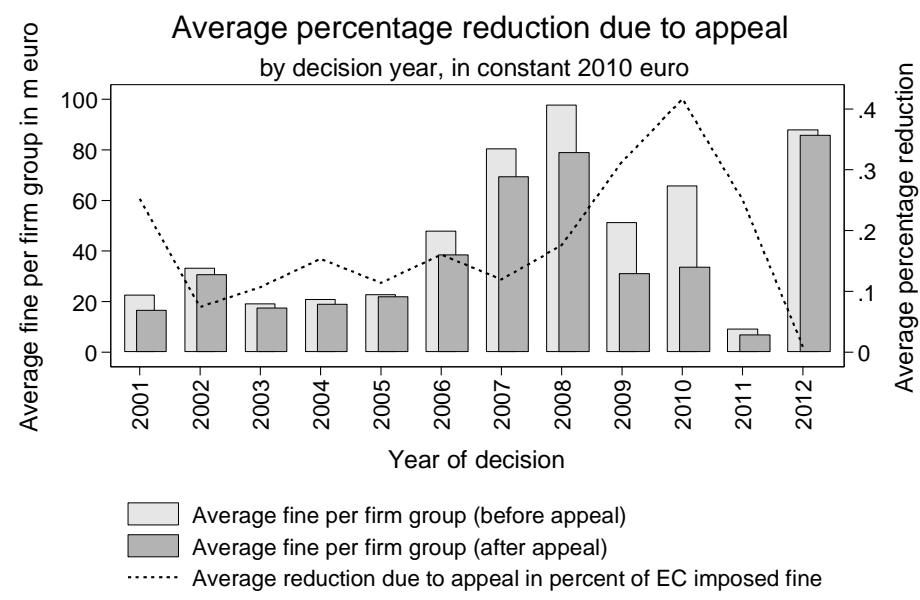

Figure 30: Average percentage reduction due to appeal Source: own figure based on ZEW cartel database

As shown in Figure 30, the average percentage reduction due to appeal experienced a rather moderate increase from about 7 percent in 2002 to 18 percent in 2008. After a substantial increase in the average percentage reduction up to 42 percent in 2010, an even more pronounced decrease was observed in the subsequent two years reaching the lowest value of about 1 percent in 2012. As already discussed above, this decrease is likely related to the introduction of the settlement procedure and the substantially reduced number of (promising) appeals in cartel cases.

\section{Summary and Conclusion}

"The competitor is our friend, and the customer is our enemy"39 once said a member of the global lysine price-fixing cartel that operated between 1992 and 1995. This statement probably qualifies as one of the best quotes describing the rationale of cartels - and the significant and long-lasting harm to customers and consumers they typically cause. However, the global lysine cartel can also act as prominent example of the severe consequences of cartelization for the involved firms after detection by a competition authority: the successive enforcement processes by the Antitrust Division of the US Department of Justice and the European Commission (EC) resulted in corporate fines of $\$ 91$ million $^{40}$ in the US and $€ 109.9$ million $^{41}$ in the EU - not to mention the additional individual fines (including 3 prison terms) in the US, further corporate fines imposed in other jurisdictions and various private damage claims.

39 The quote is taken from Connor (2008), p. 194.

40 Connor (2008), p. 450.

41 Commission Decision of 7 June 2000 relating to a proceeding pursuant to Article 81 of the EC Treaty and Article 53 of the EEA Agreement (Case COMP/36.545/F3 - Amino Acids), Official Journal of the European Communities, L 152, 2001, 24-72, pp. 68f. 
In this context, we have provided a comprehensive quantitative assessment of cartels and the related cartel enforcement process in the European Union (EU) from 2001 to 2015. In a first step, we presented a detailed characterization of all cartel cases decided by the European Commission (EC) with respect to various criteria such as the number of involved firm groups, cartel market shares and market share asymmetries, involved industries, affected countries, types of infringement, types of cartel breakdown as well as cartel duration. In a second step, we complemented this cartel-based analysis with a quantitative assessment of the public cartel enforcement process in the European Union - subdivided further into its duration, types of cartel detection, the leniency program, the settlement procedure, overall fines imposed, and the conclusive appeals process with the General Court (GC) and the European Court of Justice (ECJ).

Rather than trying to summarize the rich set of quantitative results and their interpretation, we close by characterizing the average cartel case and the average cartel enforcement process in the European Union for our observation period from 2001 to 2015. Starting with the average EU cartel, we can say that it consists of 7 firm groups stemming from 5 different countries, has a combined market share of 79 percent, operates in the manufacturing industry, uses direct price-fixing in combination with another type of infringement and lasts for 87 months before it either dies of natural causes or is detected by the European Commission.

Turning from the average cartel case to the average enforcement process in the European Union, our quantitative assessment suggest that the case investigation by the Commission lasts 51 months, followed by a 51 months review by the General Court as first-stage appellate court. The final fine for a cartel is €231 million, compared to €36 million for a firm group. In the course of the investigation by the Commission, the maximum possible fine is reduced by 45 percent - with the leniency program playing the most important role reaching a fine reduction of 29 percent (excluding the key witness). On appeal, a further reduction of 17 percent of the final fine imposed by the Commission is reached.

Our quantitative assessment of detected cartels and the respective enforcement process in the European Union suggests several avenues of future research. In addition to econometric studies on specific issues touched above - such as ex-post evaluations of the 2006 revisions of the fine guidelines and the leniency notice - promising extensions in the range of topics would, on the one hand, be comparisons of our EU findings with other enforcement regimes such as the United States or single EU Member States. On the other hand, our focus on public enforcement in this paper would suggest a complementary quantitative assessment of private enforcement activities. However, although the European Commission recently published a 
Directive on Antitrust Damages Actions ${ }^{42}$ - which is currently implemented by the Member States into their national legal systems - it appears unlikely that a sufficient amount of data for conducting quantitative studies will become available in the not too distant future.

\section{References}

Carree, M., A. Günster and M.P. Schinkel (2010), European Antitrust Policy 1957-2004: An Analysis of Commission Decisions, Review of Industrial Organization 36, 97-131.

Connor, J. (2008), Global Price Fixing, Studies in Industrial Organization, Second Edition, Heidelberg.

Harrington, J. (2006), How Do Cartels Operate?, Foundations and Trends in Microeconomics $2(1), 1-105$.

Harrington, J. and Y. Wei (2016), What Can the Duration of Discovered Cartels Tell Us About the Duration of All Cartels?, Economic Journal, forthcoming.

Hellwig, M., K. Hüschelrath and U. Laitenberger (2016), Settlements and Appeals in the European Commission's Cartel Cases: An Empirical Assessment, ZEW Discussion Paper No. 16-010, Mannheim.

Hicks, J. (1935), Annual Survey of Economic Theory: The Theory of Monopoly, Econometrica 3, 1-20.

Hoang, C., K. Hüschelrath, U. Laitenberger and F. Smuda (2014), Determinants of SelfReporting under the European Corporate Leniency Program, International Review of Law and Economics 40, 15-23.

Hüschelrath, K. and U. Laitenberger (2015), The Settlement Procedure in EC Cartel Cases: An Empirical Assessment, ZEW Discussion Paper No. 15-064, Mannheim.

Hüschelrath, K. and S. Peyer (2013), Public and Private Enforcement of Competition Law: A Differentiated Approach, World Competition Law and Economics Review 36 (4), 585-614. Hüschelrath, K. and F. Smuda (2016), The Appeals Process in the European Commission's Cartel Cases: An Empirical Assessment, Journal of Empirical Legal Studies 13 (2), 330357.

Hüschelrath, K. and J. Weigand (2013), Fighting Hard Core Cartels, in: M. Neumann and J. Weigand, The International Handbook of Competition - Second Edition, Cheltenham, 307369.

42 Directive 2014/104/EU of the European Parliament and of the Council of 26 November 2014 on certain rules governing actions for damages under national law for infringements of the competition law provisions of the Member States and of the European Union Text with EEA relevance, Official Journal of the European Union, L 349, 2014, 1-19. 
Pepall, L., D. Richards and G. Norman (1999), Industrial Organization: Contemporary Theory and Practice, Boston.

Russo, F., M.P. Schinkel, A. Günster and M. Carree (2010), European Commission Decisions on Competition: Economic Perspectives on Landmark Antitrust and Merger Cases, Cambridge.

Smuda, F., P. Bougette and K. Hüschelrath (2015), Determinants of the Duration of European Appellate Court Proceedings in Cartel Cases, Journal of Common Market Studies 53 (6), 1352-1369.

Veljanovski, C. (2011), Deterrence, Recidivism, and European Cartel Fines, Journal of Competition Law and Economics 7 (4), 871-915.

Veljanovski, C. (2007), Cartel Fines in Europe: Law, Practice and Deterrence, World Competition Law and Economics Review 30 (1), 65-86.

Wils, W. (2002), The Optimal Enforcement of EC Antitrust Law, The Hague. 